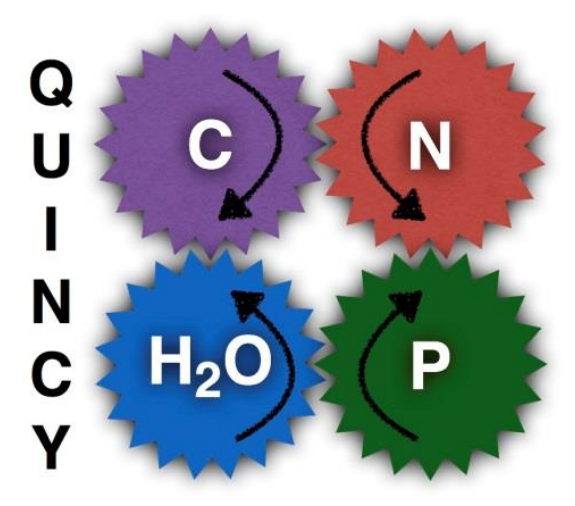

\title{
Towards physiologically meaningful water-use efficiency estimates from eddy covariance data
}

\author{
Accepted version \\ (with Permission and Acknowledgement, \\ Global Change Biology Oct. 11., 2017)
}

Jürgen Knauer, Sönke Zaehle, Belinda E. Medlyn, Markus Reichstein, Christopher A. Williams, Mirco Migliavacca, Martin G. De Kauwe, Christiane Werner, Claudia Keitel, Pasi Kolari, Jean-Marc Limousin, Maj-Lena Linderson

\section{Published in: Global Change Biology}

Reference: Knauer, J., Zaehle, S., Medlyn, B. E., Reichstein, M., Williams, C. A., Migliavacca, M., et al. (2018). Towards physiologically meaningful water-use efficiency estimates from eddy covariance data. Global Change Biology, 24(2), 694-710. doi:10.1111/gcb.13893. https://doi.org/10.1111/gcb.13893 


\title{
Towards physiologically meaningful water-use efficiency estimates from eddy covariance data
}

\author{
Jürgen Knauer ${ }^{1,2,3}$ | Sönke Zaehle ${ }^{1,4}$ | Belinda E. Medlyn ${ }^{3}$ | Markus Reichstein ${ }^{1,4}$ \\ Christopher A. Williams $^{5}$ | Mirco Migliavacca ${ }^{1}$ | Martin G. De Kauwe ${ }^{6,7}$ \\ Christiane Werner $^{8}$ | Claudia Keitel ${ }^{9}$ | Pasi Kolari ${ }^{10}$ | Jean-Marc Limousin ${ }^{11}$ | \\ Maj-Lena Linderson ${ }^{12}$
}

${ }^{1}$ Department of Biogeochemical Integration, Max Planck Institute for Biogeochemistry, Jena, Germany

${ }^{2}$ International Max Planck Research School for Global Biogeochemical Cycles (IMPRSgBGC), Jena, Germany

${ }^{3}$ Hawkesbury Institute for the Environment, Western Sydney University, Richmond, NSW, Australia

${ }^{4}$ Michael-Stifel-Center Jena for Data-Driven and Simulation Science, Jena, Germany

${ }^{5}$ Graduate School of Geography, Clark University, Worcester, MA, USA

${ }^{6}$ Department of Biological Science, Macquarie University, North Ryde, NSW, Australia

${ }^{7}$ ARC Centre of Excellence for Climate Extremes, University of New South Wales, Sydney, NSW, Australia

${ }^{8}$ Department of Ecosystem Physiology, University of Freiburg, Freiburg, Germany

${ }^{9}$ School of Life and Environmental Science, University of Sydney, Brownlow Hill, NSW Australia

${ }^{10}$ Department of Physics, University of Helsinki, Helsinki, Finland

${ }^{11}$ Centre d'Ecologie Fonctionnelle et Evolutive, Université de Montpellier, Montpellier, France

${ }^{12}$ Department of Physical Geography and Ecosystem Science, Lund University, Lund, Sweden

\section{Correspondence}

Jürgen Knauer, Department of

Biogeochemical Integration, Max Planck

Institute for Biogeochemistry, Jena,

Germany.

Email: jknauer@bgc-jena.mpg.de

Funding information

H2020 European Research Council, Grant/

Award Number: 647204

\begin{abstract}
Intrinsic water-use efficiency (iWUE) characterizes the physiological control on the simultaneous exchange of water and carbon dioxide in terrestrial ecosystems. Knowledge of iWUE is commonly gained from leaf-level gas exchange measurements, which are inevitably restricted in their spatial and temporal coverage. Flux measurements based on the eddy covariance (EC) technique can overcome these limitations, as they provide continuous and long-term records of carbon and water fluxes at the ecosystem scale. However, vegetation gas exchange parameters derived from EC data are subject to scale-dependent and method-specific uncertainties that compromise their ecophysiological interpretation as well as their comparability among ecosystems and across spatial scales. Here, we use estimates of canopy conductance and gross primary productivity (GPP) derived from EC data to calculate a measure of iWUE $\left(G_{1}\right.$, "stomatal slope") at the ecosystem level at six sites comprising tropical, Mediterranean, temperate, and boreal forests. We assess the following six mechanisms potentially causing discrepancies between leaf and ecosystem-level estimates of $G_{1}$ : (i) non-transpirational water fluxes; (ii) aerodynamic conductance; (iii) meteorological deviations between measurement height and canopy surface; (iv) energy balance non-closure; (v) uncertainties in net ecosystem exchange partitioning; and (vi) physiological withincanopy gradients. Our results demonstrate that an unclosed energy balance caused the largest uncertainties, in particular if it was associated with erroneous latent heat flux estimates. The effect of aerodynamic conductance on $G_{1}$ was sufficiently captured with a simple representation. $G_{1}$ was found to be less sensitive to meteorological deviations between canopy surface and measurement height and, given that data are appropriately filtered, to non-transpirational water fluxes. Uncertainties in the derived GPP and physiological within-canopy gradients and their implications for parameter estimates at leaf and ecosystem level are discussed. Our results highlight the importance of adequately considering the sources of uncertainty outlined here when ECderived water-use efficiency is interpreted in an ecophysiological context.
\end{abstract}

KEYWORDS

aerodynamic conductance, canopy gradients, eddy covariance, energy imbalance, intrinsic water-use efficiency, Penman-Monteith equation, slope parameter, surface conductance 


\section{1 | INTRODUCTION}

Water-use efficiency (WUE) is an important vegetation property which characterizes the coupling of the water and carbon cycles at the leaf to global scales (Beer et al., 2009; Denmead, Dunin, Wong, \& Greenwood, 1993; Farquhar, Hubick, Condon, \& Richards, 1989; Ito \& Inatomi, 2012). Understanding the physiological mechanisms that modulate WUE and being able to predict its future behavior in a changing environment is a fundamental challenge. Since the common formulation for WUE- the ratio of carbon gain to water lossis affected by both physiological and environmental factors, alternative WUE metrics are useful that aim to extract the biological component of WUE. Such metrics have the advantage of being readily comparable across atmospheric conditions and across sites, and their dynamics can be more directly linked to the underlying physiological mechanisms. For example, many authors replace actual WUE (net photosynthesis $\left(A_{n}\right) /$ transpiration) with the intrinsic WUE (iWUE $=A_{n} /$ stomatal conductance $\left(g_{s}\right)$ ) (Osmond, Björkman, \& Anderson, 1980; Schulze \& Hall, 1982). However, iWUE is still indirectly dependent on environmental conditions, particularly vapor pressure deficit (VPD) and atmospheric $\mathrm{CO}_{2}$ concentration $\left(C_{\mathrm{a}}\right)$. $\mathrm{A}$ metric that accounts for variations in these conditions is the "stomatal slope" or "slope coefficient" (" $g_{1}$ " of the optimal stomatal model derived by Medlyn et al. (2011)). This parameter is inversely related to the marginal carbon cost of water to the plant and is calculated as the slope of the relationship between $g_{s}$ and $A_{n}$, normalized for VPD and $\mathrm{CO}_{2}$ concentration (Medlyn et al., 2011). $g_{1}$ is inversely related to intrinsic water-use efficiency (iWUE), and higher values of $g_{1}$ are associated with higher intercellular $\mathrm{CO}_{2}$ concentrations $\left(C_{\mathrm{i}}\right)$. By accounting for confounding atmospheric factors, $g_{1}$ has been shown to provide valuable insights into the ecophysiological functioning of vegetation and its water-use strategy. It could, for instance, be related to wood density, which is a proxy for various plant hydraulic traits (Lin et al., 2015). $g_{1}$ is further, and in its original meaning, the key model parameter in stomatal conductance formulations embedded in ecosystem and Earth system models (Ball, Woodrow, \& Berry, 1987; Leuning, 1995; Medlyn et al., 2011). Thus, knowledge on the variation of $g_{1}$ with climate and vegetation types is essential for understanding and modeling the physiological basis of present and future terrestrial water-carbon relations.

Values of $g_{1}$ are usually inferred from gas exchange measurements on individual leaves using transparent or lighted chambers. These instruments determine $A_{n}$ and $g_{s}$ from gas concentration changes within the chamber and provide simultaneous measurements of $\mathrm{CO}_{2}$ concentration and humidity at the leaf surface, information from which $g_{1}$ can be readily inferred. One advantage of this measurement setup is that it provides conditions in which feedbacks with the physical environment (e.g., leaf boundary layer conductance) are largely controlled; thus, the information gained can be considered as purely physiological - though pitfalls exist (see Long \& Bernacchi, 2003). One disadvantage of the method is that it is laborious and time-consuming, with the consequence that measurements are often restricted to a few days and to a small selection of leaves, usually located at the top of the canopy. As a consequence, leaf gas exchange measurements and resulting $g_{1}$ estimates are prone to spatial and temporal sampling biases.

Inferring $g_{1}$ from gas exchange measurements at the ecosystem scale with the eddy covariance (EC) technique (e.g., Aubinet et al., 1999) offers the potential to circumvent these biases. This method overcomes the main limitations of leaf-level data as it provides noninvasive, continuous, and long-term measurements of carbon, water, and energy fluxes that integrate an entire ecosystem. In principle, $g_{1}$ can be estimated from EC data in the same manner as at the leaf level if $A_{n}$ and $g_{s}$ are replaced by their ecosystem-level analogs and meteorological conditions at the leaf level with those measured at the flux tower (Medlyn et al., 2017). Ecosystem-integrated $g_{s}$, i.e., canopy conductance $\left(G_{c}\right)$, is commonly derived as surface conductance $\left(G_{s}\right)$ from the inverted Penman-Monteith (PM) equation, and ecosystem net photosynthesis can be approximated by gross primary productivity (GPP) as derived from measured net ecosystem exchange (NEE) of $\mathrm{CO}_{2} . \mathrm{G}_{1}$ (capital letters denote ecosystem-level quantities in this study) at ecosystem level constitutes a WUErelated ecosystem functional property according to Reichstein, Bahn, Mahecha, Kattge, and Baldocchi (2014) and has the advantage of representing a spatial and temporal integration of vegetation gas exchange, which supposedly yields more robust and representative WUE characteristics of an ecosystem than leaf gas exchange data. This aspect is especially relevant when the vegetation is of complex vertical structure or composed of multiple species with different physiological traits, in which case it is challenging to adequately represent the entire vegetation community with point measurements.

One challenge associated with EC data is that the measured fluxes are affected by physical feedback mechanisms that hinder conclusions about the underlying physiological mechanisms, an aspect that is generally of increasing importance when the scale of measurement is increased, e.g., from leaf to ecosystem (Anderson, Kustas, \& Norman, 2003; Jarvis \& McNaughton, 1986; Knauer et al., 2017). With the fluxes and meteorological variables measured a few meters above the canopy, an additional aerodynamic conductance $\left(G_{a}\right)$ term has to be considered. Further, the EC system is unable to distinguish purely physical (i.e., evaporation) from physiologically controlled (i.e., transpiration) water fluxes. EC data are also subject to method-specific measurement errors and uncertainties. In particular, the measured energy fluxes often do not close the energy balance (Leuning, Van Gorsel, Massman, \& Isaac, 2012; Wilson et al., 2002), and the partitioning of NEE into its component fluxes involves considerable uncertainties (Desai et al., 2008; Reichstein et al., 2005; Wehr et al., 2016). In addition, possible within-canopy gradients of $g_{1}$ cannot be directly resolved with EC measurements alone.

These aspects are especially relevant in the context of a recent study that found discrepancies between leaf- and EC-based estimates of $g_{1}$ and its patterns across vegetation types (Medlyn et al., 2017). These mismatches are unlikely to result from inadequate scaling procedures of WUE from leaf to ecosystem (Launiainen, Katul, Kolari, Vesala, \& Hari, 2011; Linderson et al., 2012), but might in 
large parts be caused by methodological uncertainties in the EC data and conceptual differences between the two data sources. Thus, identifying and quantifying the potential effects of these uncertainties will be a crucial first step to reconcile estimates across scales and enable a consistent use of the two data sources in modeling and observational studies.

Here, we analyze the sensitivity of $G_{1}$ to the factors outlined above at six forest ecosystems and compare it to leaf-level $g_{1}$ estimates at the same location. The objective of this study is to quantify the effects of confounding nonphysiological factors on ecosystemlevel $G_{1}$, with the ultimate goal of deriving a physiologically meaningful WUE parameter from EC measurements that is analogous to leaf-level estimates. Such information can be used to (i) parameterize and evaluate large-scale models, (ii) obtain a characterization of ecosystem-level iWUE that is readily comparable across locations differing in their environmental conditions, and (iii) compare estimated vegetation gas exchange parameters across scales.

\section{2 | MATERIALS AND METHODS}

\section{1 | Leaf-level estimates of $g_{1}$}

Gas exchange measurements at leaf level are taken from previous studies (Table 1) and are in parts also included in the database compiled by Lin et al. (2015). Data are publicly available under https://bit bucket.org/gsglobal/leafgasexchange. Measurements were made with standard instruments mostly at the top third of the canopy for the dominant species at the site. For the analysis, the unified stomatal optimization model (Medlyn et al., 2011) was used:

$$
g_{\mathrm{s}}=g_{0}+1.6\left(1+\frac{g_{1}}{\sqrt{D_{\mathrm{s}}}}\right) \frac{A_{\mathrm{n}}}{c_{\mathrm{s}}}
$$

where $g_{0}$ is the minimum stomatal conductance $\left(\mathrm{mol} \mathrm{m}^{-2} \mathrm{~s}^{-1}\right), g_{1}$ is the stomatal slope parameter $\left(\mathrm{kPa}^{0.5}\right)$, and $A_{n}$ is net photosynthesis $\left(\mu \mathrm{mol} \mathrm{m} \mathrm{m}^{-2} \mathrm{~s}^{-1}\right) . D_{\mathrm{s}}$ is the vapor pressure deficit $(\mathrm{kPa})$, and $c_{\mathrm{s}}$ is the $\mathrm{CO}_{2}$ concentration (ppm), both at the leaf surface. $g_{1}$ was estimated from Equation (1) using nonlinear, iteratively reweighted least squares based on the R-package robustbase (Maechler et al., 2016). As in Lin et al. (2015), go was set to 0 for the entire analysis, as (i) the physiological meaning of a statistically fitted $g_{0}$ is unclear (e.g., Barnard \& Bauerle, 2013), and (ii) $g_{0}$ correlates with $g_{1}$, thus simultaneous estimation of both parameters would hamper the comparison of $g_{1}$ across datasets and sites.

\section{2 | Ecosystem-level estimates of surface conductance and $G_{1}$}

We analyzed EC data from six flux tower sites within the FLUXNET network, where colocated leaf-level measurements were available (Table 1). The EC data were taken from the FLUXNET2015 dataset (http://fluxnet.fluxdata.org/data/fluxnet2015-dataset/; accessed on 04.07.2016) and are at half-hourly or hourly resolution. The sites comprise one evergreen needle-leaf forest (FI-Hyy), two deciduous broadleaf forests (DK-Sor, US-Ha1), two evergreen broadleaf forests (AU-Tum, FR-Pue), and one evergreen tropical forest (GF-Guy). Flux data underwent standard processing, including friction velocity $\left(u_{*}\right)$ filtering (Papale et al., 2006), gap filling, and flux partitioning (Reichstein et al., 2005). Only measured flux data were used.

TABLE 1 Characteristics of eddy covariance sites and colocated leaf-level measurements used in this study

\begin{tabular}{|c|c|c|c|c|c|c|c|c|}
\hline Site & Climate $^{a}$ & Forest type & $\begin{array}{l}\text { Max. } \\
\text { LAI }\end{array}$ & $\begin{array}{l}\text { Canopy } \\
\text { height }(m)\end{array}$ & Reference EC site & $\begin{array}{l}\text { Leaf-level } \\
\mathrm{g}_{1}\left(\mathrm{kPa}^{0.5}\right)\end{array}$ & Species sampled & $\begin{array}{l}\text { Reference leaf- } \\
\text { level data }\end{array}$ \\
\hline AU-Tum & $\mathrm{Cfb}$ & Broadleaf evergreen & 2.4 & 40 & $\begin{array}{l}\text { Leuning, Cleugh, } \\
\text { Zegelin, and Hughes } \\
\text { (2005) }\end{array}$ & 3.7 & $\begin{array}{l}\text { Eucalyptus } \\
\text { delegatensis }\end{array}$ & $\begin{array}{l}\text { Medlyn, Pepper, } \\
\text { O'Grady, and } \\
\text { Keith (2007) }\end{array}$ \\
\hline DK-Sor & $\mathrm{Cfb}$ & Broadleaf deciduous & 4.5 & 25 & $\begin{array}{l}\text { Pilegaard, Ibrom, } \\
\text { Courtney, Hummelshøj, } \\
\text { and Jensen (2011) }\end{array}$ & 4.0 & Fagus sylvatica & $\begin{array}{l}\text { Linderson et al. } \\
\text { (2012) }\end{array}$ \\
\hline FI-Hyy & Dfc & Needle-leaf evergreen & 3.3 & 14 & Vesala et al. (2005) & 1.8 & Pinus sylvestris & $\begin{array}{l}\text { Kolari, Lappalainen, } \\
\text { Hänninen, and } \\
\text { Hari (2007) }\end{array}$ \\
\hline FR-Pue & Csa & Broadleaf evergreen & 3.3 & 5.5 & Rambal et al. (2003) & 1.6 & Quercus ilex & $\begin{array}{l}\text { Martin-StPaul } \\
\text { et al. (2012) }\end{array}$ \\
\hline GF-Guy & Af & Tropical evergreen & $7.0^{\mathrm{b}}$ & 35 & Bonal et al. (2008) & 4.4 & 77 species & $\begin{array}{l}\text { J. Zaragoza-Castells, } \\
\text { P. Meir, } \\
\text { O. K. Atkin, } \\
\text { Unpublished }\end{array}$ \\
\hline US-Ha1 & Dfb & Broadleaf deciduous & 4.9 & 23 & Urbanski et al. (2007) & 4.9 & $\begin{array}{l}\text { Acer rubrum, } \\
\text { Betula alleghaniensis, } \\
\text { Betula papyrifera, } \\
\text { Quercus rubra }\end{array}$ & $\begin{array}{l}\text { Bassow and } \\
\text { Bazzaz (1997) }\end{array}$ \\
\hline
\end{tabular}

${ }^{\mathrm{a}}$ Köppen-Geiger climate classification (Af = equatorial, rainforest; $\mathrm{Cfb}=$ humid, warm temperate, warm summer; $\mathrm{Csa}=$ summer dry, warm temperate, hot summer; Dfb = cold, humid, warm summer; Dfc = cold, humid, cold summer).

${ }^{b}$ Plant area index. 
Eddy covariance measurements were analyzed within a "big-leaf" model framework, in which vegetation is represented as a uniform, single plane, acting as the only flux source and sink in the ecosystem (e.g., Raupach \& Finnigan, 1988). For the purpose of this study, a data-oriented, top-down approach based on the big-leaf framework was preferred over more detailed representations of the ecosystem, such as two-layer (vegetation-soil, e.g., Shuttleworth \& Wallace, 1985) or dual-source models (sun-shade, e.g., de Pury \& Farquhar, $1997)$ as these representations would require additional parameterization that cannot be obtained from single-level flux measurements.

Bulk surface conductance $\left(G_{\mathrm{s}}, \mathrm{m} / \mathrm{s}\right)$ was calculated from the inverted Penman-Monteith (PM) equation (Monteith, 1965):

$$
G_{\mathrm{s}}=\frac{\lambda E G_{\mathrm{a}} \gamma}{s\left(R_{\mathrm{n}}-G-S\right)+\rho c_{\mathrm{p}} G_{\mathrm{a}} D_{\mathrm{a}}-\lambda E(s+\gamma)}
$$

where $\lambda E$ is the latent heat flux $\left(\mathrm{W} / \mathrm{m}^{2}\right), G_{a}$ is the bulk aerodynamic conductance for water vapor $(\mathrm{m} / \mathrm{s}), \gamma$ is the psychrometric constant $(\mathrm{Pa} / \mathrm{K}), \mathrm{s}$ is the slope of the saturation vapor pressure curve $(\mathrm{Pa} / \mathrm{K}), R_{\mathrm{n}}$ is the net radiation $\left(\mathrm{W} / \mathrm{m}^{2}\right), G$ is the ground heat flux $\left(\mathrm{W} / \mathrm{m}^{2}\right), S$ is the sum of all energy storage fluxes $\left(\mathrm{W} / \mathrm{m}^{2}\right), \rho$ is the air density $\left(\mathrm{kg} / \mathrm{m}^{3}\right), c_{\mathrm{p}}$ is the heat capacity of dry air $\left(\mathrm{J} \mathrm{kg}^{-1} \mathrm{~K}^{-1}\right)$, and $D_{\mathrm{a}}$ is the air vapor pressure deficit $(\mathrm{Pa})$. For some sites, $G$ was measured with heat flux plates, whereas measurements of $S$ were not available and set to 0 for all sites. The PM equation was applied at the half-hourly or hourly timescale, thereby accounting for sub-diurnal variations in meteorological drivers. The approach is further based on similar assumptions as the EC technique (see, e.g., van Dijk et al., 2015 and references therein). $G_{\mathrm{s}}$ subsumes canopy conductance $\left(G_{\mathrm{c}}\right)$, as well as conductances from the soil and water intercepted by the canopy. Consequently, $G_{s}$ is only a physiologically meaningful quantity $\left(G_{s} \approx G_{c}\right)$ in time periods when vegetation is active, and the vegetation and soil surfaces are not wet. To ensure this to be the case, precipitation events, as well as the subsequent $48 \mathrm{hr}$, were excluded, and the analysis was restricted to daylight conditions (PPFD $>200 \mu \mathrm{mol} \mathrm{m}{ }^{-2} \mathrm{~s}^{-1}$ ) and to time periods within the growing season. Data were considered to be in the growing season when smoothed (15-day moving average) daily GPP exceeded half of the 95th percentile of all daily GPP values in a year (e.g., Fig. S1). Further filtering criteria included the following: air temperature $>5^{\circ} \mathrm{C}$, relative humidity $<95 \%, \lambda E>0 \mathrm{~W} / \mathrm{m}^{2}$, and $\left(R_{\mathrm{n}}-G\right)>0 \mathrm{~W} / \mathrm{m}^{2}$. A site- and year-specific $u_{*}$ threshold, as provided by the FLUXNET2015 dataset, was applied. Atmospheric $\mathrm{CO}_{2}$ data were processed as described in Medlyn et al. (2017). Analysis steps performed in this study are available in the language R under https:// bitbucket.org/juergenknauer/g1_leaf_ecosystem.

Ecosystem-level $G_{1}$ was calculated in the same manner as at the leaf level (Equation 1 ) but with $g_{s}$ and $A_{n}$ replaced by $G_{s}$ and GPP (representing carboxylation minus photorespiration), respectively (Equation 3, data shown in Figs S2 and S3). Further, $D_{\mathrm{s}}$ and $c_{\mathrm{s}}$ were replaced by the respective measurements $\left(D_{\mathrm{a}}\right.$ and $\left.C_{\mathrm{a}}\right)$ at the flux tower:

$$
G_{s}=G_{0}+1.6\left(1+\frac{G_{1}}{\sqrt{D_{a}}}\right) \frac{G P P}{C_{a}}
$$

$G_{1}$ in Equation (3) was determined on an annual basis using the same nonlinear regression method as for the determination of $g_{1}$ at leaf level.

\subsection{Factors affecting $G_{1}$ estimates}

\subsection{1 | Non-transpirational water fluxes}

$G_{\mathrm{s}}$ as calculated from Equation (2) is affected by both transpiration and solely physically driven water fluxes (i.e., bare soil and interception evaporation); thus, $G_{c}$ and $G_{1}$ are expected to be increasingly overestimated with increasing contribution of non-transpirational water fluxes to ET (Paw \& Meyers, 1989). To analyze the sensitivity of $G_{1}$ to these contributions, we calculated $G_{1}$ for successively increasing time periods following a rainfall event. Time after rainfall is considered as an inverse proxy for the contribution of physical water fluxes to ET, which have been observed to decrease exponentially with time after rainfall (e.g., Kelliher et al., 1998), but not in all ecosystems (e.g., Dubbert et al., 2014). Since dew evaporation is, unlike soil and interception evaporation, not necessarily excluded by the rainfall filter, we additionally tested the effect of a simple dew evaporation filter on estimated annual values of $G_{1}$. The dew filter was applied if the likelihood of dew evaporation was high, which was considered the case if relative humidity exceeded $95 \%$ and the radiation balance turned negative $\left(R_{\mathrm{n}}<0 \mathrm{~W} / \mathrm{m}^{2}\right)$ at night. If these conditions were met, the PPFD threshold was raised to $600 \mu \mathrm{mol} \mathrm{m} \mathrm{m}^{-2} \mathrm{~s}^{-1}$ in the following morning.

\subsection{2 | Aerodynamic conductance}

The bulk aerodynamic conductance for water vapor $\left(G_{a}\right)$ between the evaporating surface and the measurement height of the flux is an integral part of the PM equation (Equation 2). $G_{a}$ can be conceptualized as the inverse of two resistances in series: $G_{a}=1$ / $R_{\mathrm{a}}=\left(R_{\mathrm{aM}}+R_{\mathrm{b}}\right)^{-1}$, where $R_{\mathrm{aM}}$ is the turbulent aerodynamic resistance for momentum, and $R_{\mathrm{b}}$ is the (bulk) canopy boundary layer resistance or "excess resistance" (Verma, 1989).

We tested the effect of calculating $G_{a}$ in Equation (2) using three different approaches of increasing complexity:

1. $G_{a}$ set to infinity, corresponding to the assumption that the ecosystem is aerodynamically fully coupled to the atmosphere:

$$
G_{\mathrm{a}, \text { fcoupled }}=\infty
$$

2. $G_{a}$ calculated from wind speed $u(\mathrm{~m} / \mathrm{s})$ and friction velocity $u_{*}$ $(\mathrm{m} / \mathrm{s})$ under the assumption of a logarithmic wind profile above the canopy. $R_{\mathrm{b}}$ follows an empirical dependence on $u *$ according to Thom (1972):

$$
1 / G_{\mathrm{a}, \mathrm{empGb}}=\frac{u}{u_{*}^{2}}+6.2 u_{*}^{0.67}
$$

Note that the first term of Equation (5) implicitly accounts for the effects of atmospheric stability on $G_{a}$.

3. As Equation (5) but with the empirical $R_{\mathrm{b}}$ model replaced by a physically based formulation according to Su, Schmugge, Kustas, and Massman (2001), a simplification of the model developed by Massman (1999): 


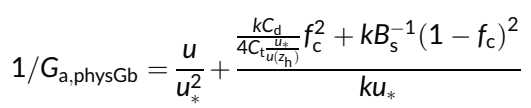

where $k=0.41$ is the von Kármán constant, $C_{d}$ is a foliage drag coefficient, assumed constant with a value of 0.2 (Massman, 1999), $C_{\mathrm{t}}$ is the heat transfer coefficient of the leaf, $f_{\mathrm{c}}$ is fractional canopy cover, $u\left(z_{h}\right)$ is wind speed at canopy height $(\mathrm{m} / \mathrm{s})$, and $B_{s}^{-1}$ is the inverse Stanton number for bare soil surface. $C_{t}$ depends primarily on the leaf characteristic dimension $D_{1}(\mathrm{~m}$; values are taken from the literature, Table S1), and $f_{\mathrm{c}}$ was estimated from LAI (for further details, see Supporting Information).

To test the sensitivity of $G_{1}$ to different formulations of $G_{a}, G_{s}$ (Equation 2) and $G_{1}$ (Equation 3) were calculated with $G_{a}$ given by Equations (4)-(6). Throughout the following analysis, $G_{a, e m p G b}$ (Equation 5) was used.

\subsection{3 | Meteorological deviations between measurement height and canopy surface}

A finite $G_{a}$ causes the meteorological conditions at the canopy surface to differ from those measured a certain distance above the canopy (e.g., Grantz \& Meinzer, 1990). These deviations are important to consider since the conditions at the canopy surface are physiologically more relevant than those in the air above the canopy. Obtaining representative measurements of canopy surface micrometeorology is challenging, but surface temperature and humidity can be readily inferred from the inverted bulk transfer equations of sensible and latent heat if an estimate of $G_{a}$ is available. Aerodynamic canopy surface temperature $\left(T_{0}\right)$ is then given by:

$$
T_{0}=T_{a}+\frac{H}{\rho G_{a} c_{p}}
$$

where $T_{\mathrm{a}}$ is air temperature $\left({ }^{\circ} \mathrm{C}\right)$ measured at sensor height, and $H$ is sensible heat flux $\left(\mathrm{W} / \mathrm{m}^{2}\right)$. Vapor pressure at the canopy surface $e_{0}$ $(\mathrm{Pa})$ is given by:

$$
e_{0}=e_{\mathrm{a}}+\frac{\lambda E \gamma}{\rho G_{\mathrm{a}} c_{\mathrm{p}}}
$$

where $e_{\mathrm{a}}$ is air vapor pressure (Pa). VPD at the canopy surface $\left(D_{0}\right)$ is given by Equations (7) and (8):

$$
D_{0}=E_{\text {sat }}\left(T_{0}\right)-e_{0}
$$

where $E_{\text {sat }}\left(T_{0}\right)$ is the saturation vapor pressure at temperature $T_{0}$. Likewise, $\mathrm{CO}_{2}$ concentration at the canopy surface $\left(C_{0}\right)$ can be approximated by:

$$
C_{0}=C_{a}+\frac{N E E}{G_{a}}
$$

where $G_{a}$ is for $\mathrm{CO}_{2}$ and in $\mathrm{mol} \mathrm{m}^{-2} \mathrm{~s}^{-1}$.

$G_{1}$ (Equation 3) was recalculated with $D_{a}$ and $C_{a}$ at measurement height replaced by their equivalents at the canopy surface $\left(D_{0}\right.$ and
$C_{0}$, respectively), as given by Equations (9) and (10). Note that the calculated $G_{s}$ (Equation 2) remains unchanged as the PM equation already accounts for meteorological deviations between the surface and measurement height.

\subsection{4 | Energy balance closure}

The PM equation that is inverted to estimate $G_{s}$ (Equation 2) in this study assumes that the energy balance at the land surface is closed, i.e.:

$$
A=R_{\mathrm{n}}-G-S=H+\lambda E
$$

where $A$ is the available energy, $R_{\mathrm{n}}$ is the net radiation, $G$ is the ground heat flux, $S$ is the sum of all ecosystem storage terms (see, e.g., Leuning et al., 2012), $\lambda E$ is the latent heat flux, and $H$ is the sensible heat flux (all in $\mathrm{W} / \mathrm{m}^{2}$ ). A common issue observed for EC data is that the energy balance is not closed, as the turbulent fluxes (right part of Equation 11) typically do not sum up to the available energy. We tested the sensitivity of an unclosed energy balance to estimates of $G_{s}$ derived from the $P M$ equation and the corresponding $G_{1}$ considering three hypothetical extreme cases which differ with respect to the attribution of the residual of the energy balance closure (residual $=A-(H+\lambda E))$ :

1. All error in $H$ (denoted as $G_{s, H} ; G_{1, H}$ ): Both $A$ and $\lambda E$ are assumed to be correctly measured, and the residual is entirely ascribed to $H$. This case is implied by the PM equation (Equation 2).

2. All error in $\lambda E\left(G_{s, \lambda E} ; G_{1, \lambda E}\right)$ : Both $A$ and $H$ are assumed to be correctly measured, and the residual is entirely ascribed to $\lambda E$, i.e., $\lambda E$ is recalculated as $\lambda E=A-H$.

3. All error in $A\left(G_{\mathrm{s}, \mathrm{A}} ; G_{1, \mathrm{~A}}\right)$ : The turbulent fluxes $H$ and $\lambda E$ are assumed to be correctly measured, and the energy imbalance is caused by an overestimation of $A$ as a result of missing or inappropriate measurements of $G$ and/or the components of $S$ (i.e., $A=\lambda E+H)$.

For comparison, $G_{s}$ was additionally calculated using $\lambda E$ adjusted according to the Bowen ratio method (Twine et al., 2000), which assumes that the residual of the energy balance is attributed to $H$ and $\lambda E$ according to the Bowen ratio ( $H / \lambda E$; see http://fluxnet.fluxda ta.org/data/fluxnet2015-dataset/data-processing/ for details on the calculation). Note that this approach, in contrast to the three cases considered above, does not force the energy balance to be closed at the sub-diurnal timescale.

The degree of the energy balance non-closure was quantified as the energy balance ratio (EBR):

$$
\mathrm{EBR}=\frac{\sum(H+\lambda E)}{\sum\left(R_{\mathrm{n}}-G-S\right)}
$$

where the individual energy balance components are either half-hourly/hourly values or summed up over a specified time period. 


\subsection{5 | NEE partitioning}

The eddy covariance technique measures the NEE of $\mathrm{CO}_{2}$ between the ecosystem and the atmosphere, but not its component fluxes GPP and ecosystem respiration $\left(R_{\text {eco }}\right)$, which have to be estimated using flux partitioning algorithms. These algorithms, described below, can be classified into two main approaches: one that extrapolates nighttime NEE data to daytime, and one that fits light response curves to daytime NEE measurements. We calculate $G_{1}$ (Equation 3) using GPP derived from both approaches to assess the uncertainty in $G_{1}$ arising from uncertainties in the GPP estimates. The nighttime data-based approach (Reichstein et al., 2005) (denoted as $\left.G P_{n t} ; G_{1, n t}\right)$ relies on the use of a temperature response function fitted to nighttime NEE ( $=R_{\text {eco }}$ ), which is then extrapolated to daytime conditions. The temperature response function (based on air temperature; Lloyd \& Taylor, 1994) considers a time-varying base respiration, which implicitly accounts for additional environmental factors affecting $R_{\text {eco. The daytime data-based approach }}$ (Lasslop et al., 2010) $\left(G P_{\mathrm{dt}} ; G_{1, \mathrm{dt}}\right)$ fits a hyperbolic light response curve to daytime NEE. The function additionally accounts for temperature effects on $R_{\text {eco }}$ and for VPD effects on GPP. We compared values of $G_{1, \mathrm{nt}}$ and $G_{1, \mathrm{dt}}$.

\subsection{6 | Within-canopy gradients}

Gradients of $g_{1}$ within the canopy cannot be directly inferred from eddy covariance data. Instead, the $g_{1}$ gradients were assessed with an integrative approach using both the EC data and a simple canopy model. The model simulates radiative transfer separately for sunlit and shaded fractions of the canopy (Spitters, 1986), which is separated into three vertical layers. Stomatal conductance and photosynthesis are modeled according to Equation (1) (Medlyn et al., 2011) and Farquhar, von Caemmerer, and Berry (1980) for each layer and are upscaled to the canopy level with the leaf area index (LAI). The model simulations were used to calculate the relative contribution of $G_{c}$ from each layer to the total $G_{c}$. This fraction was considered as a proxy of the fraction of the $G_{1}$ signal coming from a certain layer (e.g., if $G_{c}$ of the lowest layer contributed $20 \%$ to the total $G_{c}$, its contribution to the derived $G_{1}$ value was also assumed $20 \%$ ). The $E C$ data were then binned according to the relative contribution of $G_{c}$, and $G_{1}$ was estimated for each bin using Equation (3). Thus, the sun-shade radiation model served only to estimate the relative contribution of each canopy layer to $G_{c}$, whereas $G_{1}$ was directly estimated from the EC data and not from the modeled fluxes. Conditions where $\lambda E$ exceeded $A$ were excluded. A random forest model (see Supporting Information) was used to explain the response of $G_{1}$ to the contribution of the respective canopy layer as well as other variables. Subsequently, the marginal effect of the contribution of the respective layer on $G_{1}$ was calculated, and a linear regression model was fitted to the resulting partial dependence function. An extrapolation of this linear regression fit to 1 gave an estimate of the corresponding $G_{1}$ value of the layer. The estimated withincanopy gradients were then compared to the estimated $g_{1}$ from leaf- level measurements made at different levels in the canopy for the sites DK-Sor and US-Ha1.

\section{3 | RESULTS}

Figure 1 shows time series of $G_{1}$ for the EC sites considered in this study as well as available leaf-level estimates of $g_{1}$ collected at the same location. The two estimates show a relatively good agreement for AU-Tum, but different magnitudes at the other sites, where both lower (GF-Guy, US-Ha1) and higher (FI-Hyy, FR-Pue) estimates were estimated from EC data. Ecosystem-level $G_{1}$ values were robust against alternative data filters with respect to the applied growing season and radiation thresholds (Fig. S4), but showed high interannual variability which could not be attributed to a single cause. In the following sections, we present the potential effects of different factors possibly contributing to the mismatch between the estimates from the two different data sources.

\section{1 | Non-transpirational water fluxes}

$G_{1}$ calculated with successively longer time periods after the last rainfall event removed (Figure 2) showed the steepest decrease in the first hours after rain followed by a more moderate decline for all sites except US-Ha1. This pattern is likely to reflect the decreasing fraction of soil and interception evaporation on ET with time after rainfall, which is associated with a decrease of nonphysiological contributions to the inferred $G_{s}$ (Equation 2). Similar effects are expected from dew evaporation. However, the removal of time periods that are likely to be affected by dew evaporation did not result in noticeable changes in the $G_{1}$ estimates (Fig. S5). The calculated $G_{1}$ still shows a significant decrease after 3 days for some sites (e.g., $9 \%$ for FR-Pue, 19\% for DK-Sor), which suggests a significant contribution of sustained soil evaporation. However, there is no clear relationship between the sensitivity of $G_{1}$ to the excluded time period after rainfall events and the LAl of the ecosystem, which indicates that the ongoing decline in $G_{1}$ is not driven solely by soil evaporation. Data several days after the last rainfall might, in addition, be affected by the onset of drought stress, albeit the most severe drought conditions are filtered out by the GPP-based growing season filter (Fig. S1)

\section{2 | Aerodynamic conductance}

The different $G_{a}$ formulations (Equations 4-6; Fig. S6) inserted into the inverted $P M$ equation (Equation 2) resulted in similar $G_{1}$ estimates, except for the formulation where $G_{a}$ was assumed infinite $\left(G_{a, \text { fcoupled; }}\right.$ Equation 4) (Figure 3). The fully coupled assumption significantly overestimates $G_{\mathrm{s}}$ (Fig. S7a) and consequently $G_{1}$ (Figure 3a) for all site years. Compared to the reference formulation $\left(G_{a, e m p G b}\right.$; Equation 5), the overestimation of $G_{1}$ resulting from neglecting $G_{a}$ varied between $17 \%$ and $80 \%$ (site averages; mean of $50 \%$ over all site years) and depended not only on the magnitude of $G_{a}$ but also 


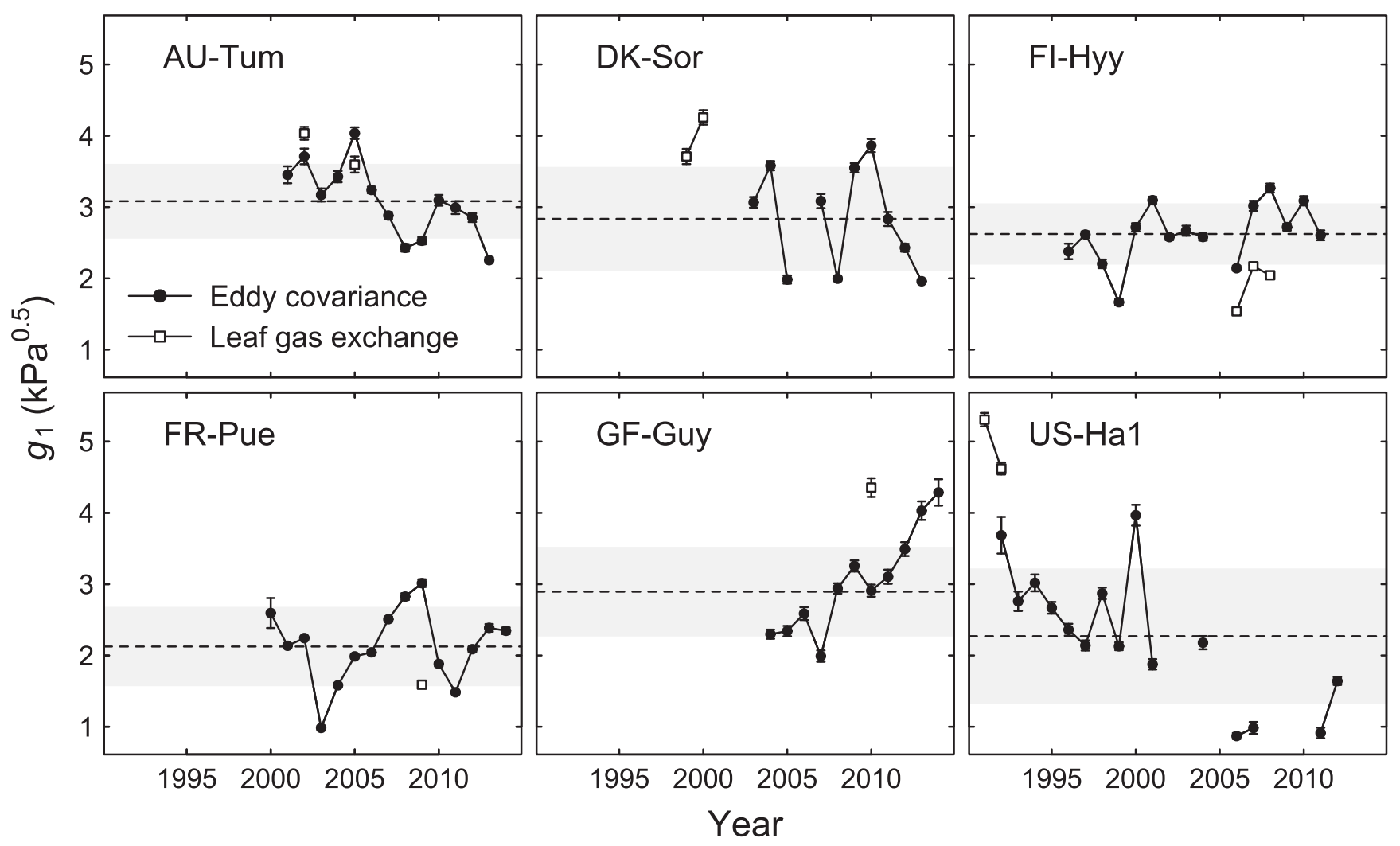

FIGURE 1 Time series of annual estimates of $G_{1}$ from eddy covariance (EC) data (filled circles) and $g_{1}$ from leaf gas exchange data taken at the top third of the canopy (open squares). For the EC data, $G_{1}$ was calculated using the following settings: $48 \mathrm{hr}$ after rainfall removed, $G_{a}$ calculated from Equation (5) ( $\left.G_{a, e m p G b}\right)$, surface conditions, and $G_{1, \mathrm{H}}$. Error bars indicate standard errors, dashed lines the mean across all years, and gray shaded areas the standard deviation of all annual $G_{1}$ values

on the evaporative fraction $\left(\lambda E / R_{\mathrm{n}}\right.$; Fig. S8) (Raupach \& Finnigan, 1988). The $G_{\text {a,physGb }}$ model gave similar results for $G_{1}$ than the simpler $G_{a, e m p G b}$ formulation. The two estimates did not differ by more than $10 \%$ for $90 \%$ of all site years. Differences between $G_{a, e m p G b}$ and $G_{a, p h y s G b}$ resulted solely from the boundary layer part $\left(R_{\mathrm{b}}\right.$, second term in Equations 5 and 6), which depends only on $u_{*}$ in the empirical formulation $\left(G_{a, e m p G b}\right)$, whereas it is affected by various additional aerodynamic properties in the physically based model $\left(G_{\mathrm{a},-}\right.$ physGb). In both formulations, $R b$ accounts for one-third to more than one half of the total aerodynamic resistance (Table S1). The $G_{a, p h y s G b}$ model tends to predict lower $G_{a}$ for broad-leaved vegetation (e.g., DK-Sor, GF-Guy) which reflects the formation of a thicker boundary layer around larger leaves (Fig. S6). The strong dependence of $G_{a}$ on the leaf characteristic dimension $\left(D_{1}\right)$ in this formulation (see

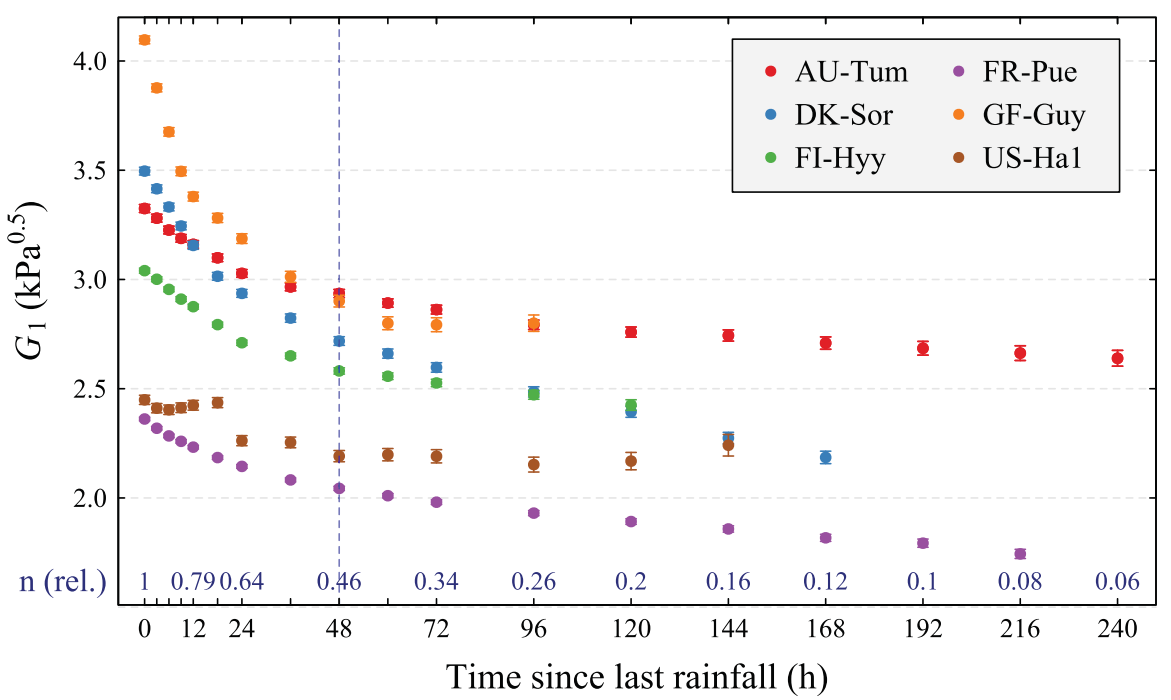

FIGURE $2 G_{1}$ calculated excluding successively longer time periods after the last rainfall event removed (time since rainfall is considered as a proxy for the contribution of physical evaporation on ET). $G_{1}$ is only shown if the number of data exceeds $10 \%$ of all filtered data. $n$ (rel.) denotes the relative amount of remaining data compared to no filter applied. The dashed blue line indicates the rainfall filter as applied in this study $(48 \mathrm{hr})$. Error bars indicate standard errors 
FIGURE 3 Mean annual $G_{1}$ estimated (Equation 3) with different calculation methods of aerodynamic conductance $\left(G_{a}\right)$ used for the calculation of surface conductance $\left(G_{s}\right.$; Equation 2). Estimated $G_{1}$ using $G_{a}$ estimated from wind speed and friction velocity and an empirical canopy boundary layer conductance $\left(G_{b}\right)$ model ( $G_{a, e m p G b}$; Equation 5$)$ is compared to (a) the fully coupled case $\left(G_{\text {a,fcoupled; }}\right.$; Equation 4) and (b) a physically based $G_{b}$ formulation ( $G_{a, p h y s G b}$; Equation 6). Blue lines indicate reduced major axis (RMA) regression fits. Error bars indicate standard errors
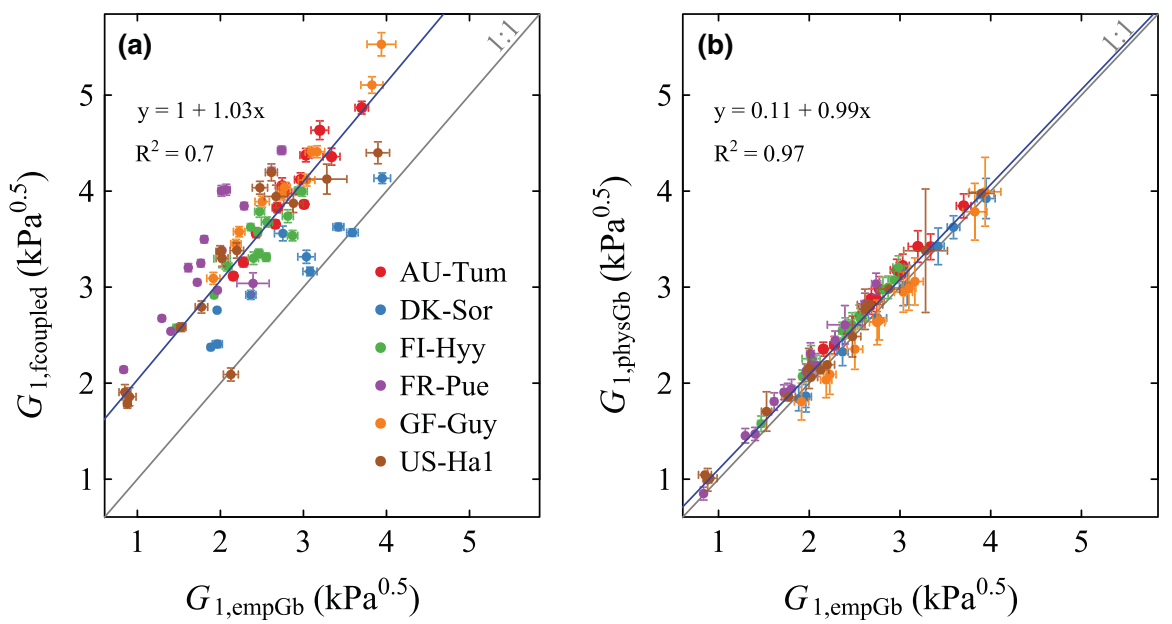

Equations S7 and S8) is associated with large uncertainties in $G_{a}$ that propagate to $G_{\mathrm{s}}$ (Fig. S7b) and $G_{1}$. Assuming a standard deviation of $25 \%$ of the average $D_{1}$ resulted in uncertainties in $G_{1}$ that mostly encompassed the $G_{1}$ values calculated using the empirical $G_{a, e m p G b}$ formulation (Figure $3 b$ ).

\section{3 | Surface conditions}

The inferred canopy surface conditions from the inverted bulk transfer equations for $\lambda E$ and $H$ (Equations 7-9 using $G_{a, e m p G b}$ (Equation 5)) indicate that the canopy surface is in most conditions warmer (median c. $2^{\circ} \mathrm{C}$ ) and more humid (median c. $0.1 \mathrm{kPa}$ ) than the air at measurement height (Fig. S9a,b). The temperature effect on VPD through an increase in $E_{\text {sat }}$ was stronger than the effect of an increase in humidity, resulting in a mostly higher VPD (median c. $0.1-0.2 \mathrm{kPa}$ ) at the vegetation surface compared to the air above $\left(D_{0}>D_{a}\right.$; Figures 4a and S9c). Based on the theory elaborated by Jarvis and McNaughton (1986), Magnani, Leonardi, Tognetti, Grace, and Borghetti (1998) have shown that the difference between $D_{0}$ and $D_{a}$ can be expressed as a rather complex function of the relative importance of imposed and equilibrium ET, the degree of canopyatmosphere decoupling, and $G_{c}$. In general, the deviations are expected to be large when the degree of decoupling is high, $G_{c}$ is low, and the difference of equilibrium and imposed ET is large (Magnani et al., 1998). The predominantly high deviations found for FRPue, for instance, can be linked to the low $G_{c}$ relative to the other sites. The inferred molar concentration of $\mathrm{CO}_{2}$ at the canopy surface $\left(C_{0}\right)$ was lower than that in the air $\left(C_{a}\right)$ as a consequence of vegetation uptake. The effect varied among sites depending on GPP and $G_{a}$ (Equation 10), and typically ranged between 0 and $15 \mathrm{ppm}$.

The estimated $G_{1}$ using $C_{0}$ (Equation 3 ) was only marginally lower than the original estimate using $C_{a}(2 \%-4 \%$; Figure $4 c)$. Replacing $D_{a}$ in Equation (3) with $D_{0}$ had the opposite effect and led to slightly higher $G_{1}$ estimates, but the effect was again small $(5 \%-$ $15 \%)$. Owing to their minor and opposite effects on $G_{1}$, the substitution of both $D_{a}$ and $C_{a}$ with their analogs at the canopy surface $D_{0}$ and $C_{0}$ in Equation (3) resulted in marginal increases in $G_{1}(2 \%-13 \%$; Figure 4c).

\section{4 | Energy balance}

Figure $5 \mathrm{a}-\mathrm{c}$ depicts mean diurnal courses of the measured energy balance components for the three sites FI-Hyy, AU-Tum, and FRPue. The available energy $A$, represented by $A=R_{n}-G$ (black line), almost always exceeds the sum of the turbulent energy fluxes $(H+\lambda E$; green line), indicating a non-closed energy balance. The degree of closure of the energy balance was represented by the energy balance ratio (EBR, Equation 12; orange line). The deviation from a closed energy balance (i.e., the difference between $A$ and $H+\lambda E$ or the residual of the energy balance closure, respectively) varied among sites. The mean EBR amounts to $0.83,0.85$, and 0.68 for Fl-Hyy, AU-Tum, and FR-Pue, respectively, and is thus in the range of previously reported average values for the FLUXNET network (Stoy et al., 2013; Wilson et al., 2002). The diurnal course of the EBR changed markedly throughout the day for all sites but in a different manner. Fl-Hyy and AU-Tum showed a consistent increase in the EBR from the morning to the evening with the energy balance being closed in the late afternoon and evening hours (EBR $\sim 1$ ). This pattern is characteristic for FLUXNET sites (Wilson et al., 2002). FRPue, in contrast, showed the opposite pattern and a mostly decreasing EBR throughout the day.

The fact that the EBR is smaller than 1 for most conditions has consequences for $G_{s}$ inferred from the inverted PM equation (Equation 2), as this equation was derived under the assumption of a closed energy balance. The error associated with the inferred $G_{s}$ depends on which components of the surface energy balance (Equation 11) are inadequately measured or (not) accounted for. Assigning the residual entirely to either $H, \lambda E$, or $A$ served to assess the maximum uncertainty in $G_{s}$ arising from a non-closed energy balance. The assumption that the energy balance non-closure is completely a result of an underestimate of $H$ ("all error in $H$ " case), as implicitly assumed by the PM equation, consistently led to the lowest $G_{s}$ values in case of an EBR $<1$. Assigning the residual energy entirely to A by recalculating it as $A=H+\lambda E$ gives slightly higher estimates compared to the first case. By contrast, assuming that all the error is in $\lambda E$ (i.e., $\lambda E$ recalculated as $\lambda E=A-H$ ) yields significantly higher $G_{\mathrm{s}}$ estimates, reaching more than $100 \%$ overestimation compared to 

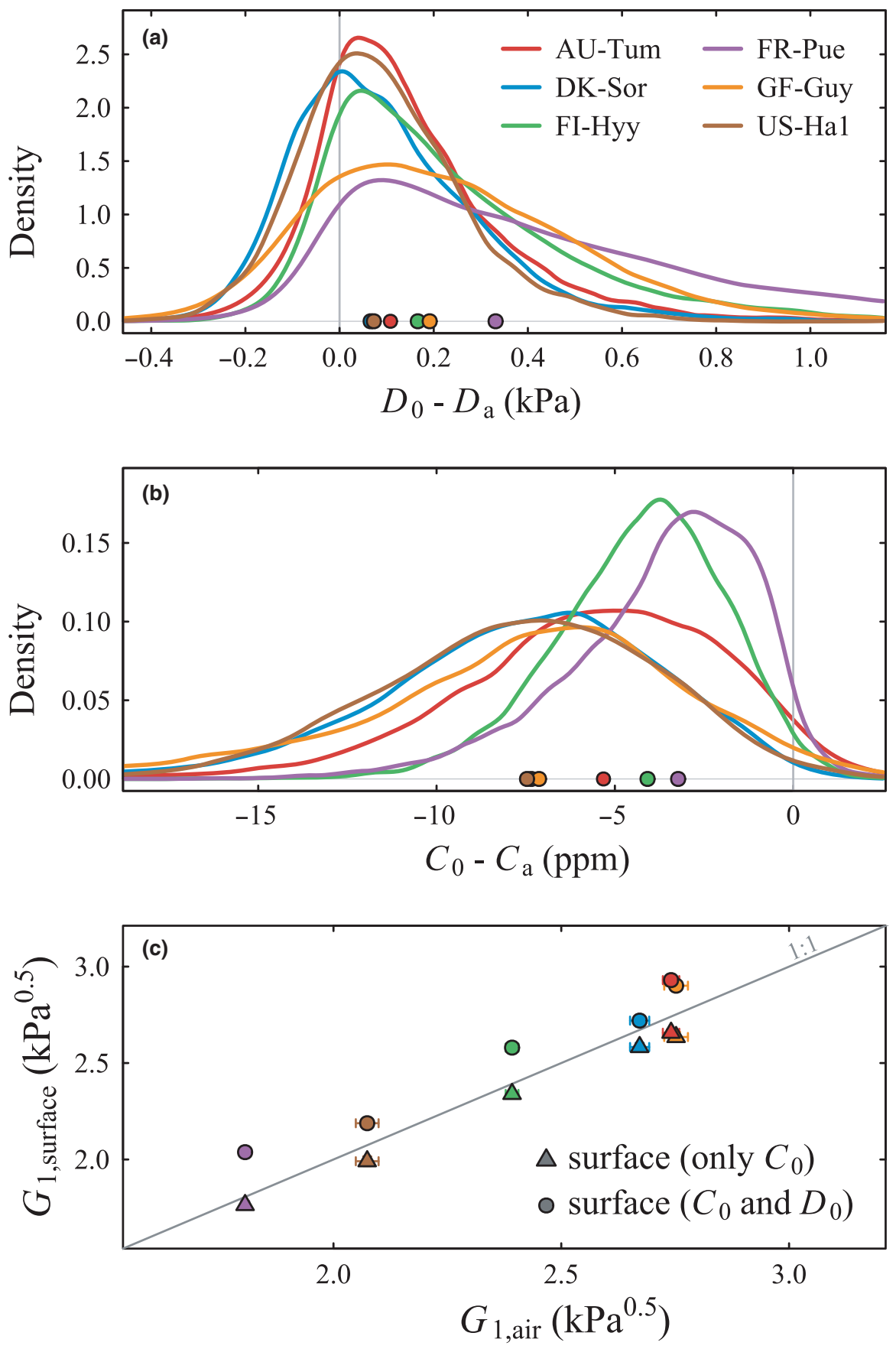

FIGURE 4 Difference between inferred canopy surface conditions and measurements above the canopy for (a) vapor pressure deficit $(D)$ and (b) $\mathrm{CO}_{2}$ concentration (C), as well as (c) the resulting effects on $G_{1}$. Canopy surface $D$ $\left(D_{0}\right)$ was calculated from the inverted bulk transfer relations of latent and sensible heat flux (Equations 7-9), and the $\mathrm{CO}_{2}$ concentration at the canopy surface $\left(C_{0}\right)$ was calculated from measured net ecosystem exchange (Equation 10). For all calculations, $G_{a}$ from Equation (5) was used. The filled circles in (a) and (b) indicate the medians of the distribution functions. $G_{1}$ in (c) represents the site mean over all available years (error bars indicate standard errors) the reference case (all error in $H$ ) for all three sites. The difference between the $G_{s}$ estimates from the three cases scales with the EBR. These three $G_{s}$ estimates are identical if EBR $=1$ and deviate for both lower and higher EBR values. The "Bowen ratio adjusted" case shows intermediate $G_{s}$ values for most conditions but it may give

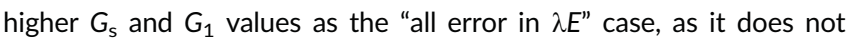
force the energy balance to be closed on the sub-diurnal timescale. Importantly, diurnal variations in the EBR as found for all three sites affect the temporal behavior of $G_{s}$ throughout the day (Figure $5 d-f$ ).

The uncertainty in $G_{s}$ due to the non-closure of the energy balance propagates to the uncertainty in $G_{1}$, which shows a similar behavior as $G_{\mathrm{s}}$ and the highest values if the residual is attributed to $\lambda E$ (Figure $5 \mathrm{~g}-\mathrm{i}$ ). $G_{1}$ shows an even higher sensitivity to the EBR. This can be explained by the fact that the estimated $G_{1}$, in addition to $G_{s}$, responds to VPD and $C_{a}$, whose diurnal courses amplify the response of $G_{1}$ to the EBR (Equation 3). Importantly, not only the magnitude of $G_{1}$ but also its diurnal course is affected. For instance, $\mathrm{G}_{1}$ at $\mathrm{FI}-\mathrm{Hyy}$ and $\mathrm{AU}$-Tum show a steady decrease if the residual is assigned to $\lambda E$, but constant or slightly increasing values through most parts of the day if it is assigned to $H$ or $A$ (Figure $5 \mathrm{~g}, \mathrm{~h}$ ).

The sensitivity of $G_{\mathrm{s}}$ to an unclosed energy balance as quantified by the EBR (Equation 12) is illustrated in Figure 6. There is a high variability of the half-hourly EBR at each site, though most of the data are characterized by an EBR between 0.5 and 1.2, depending 

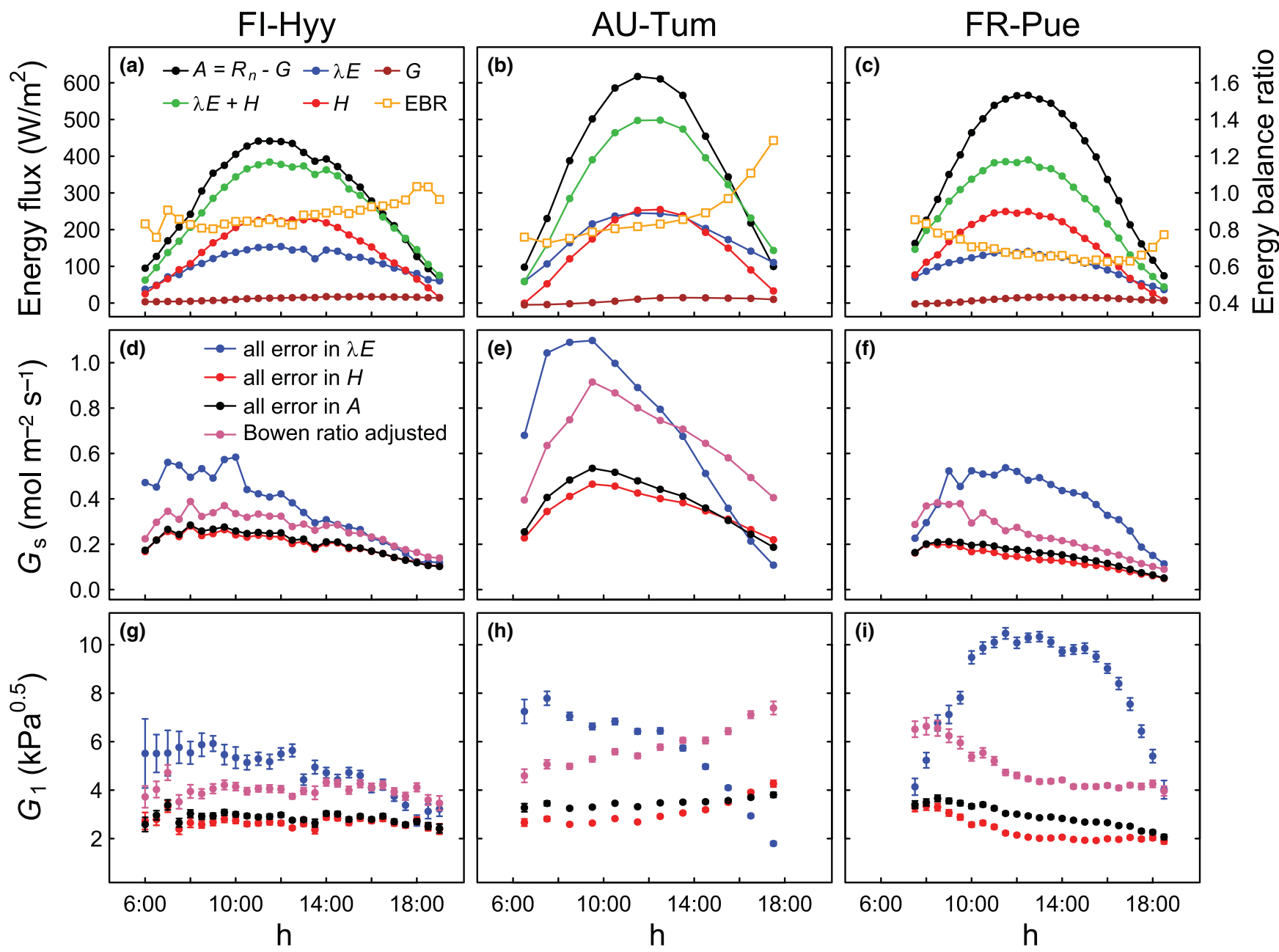

FIGURE 5 Mean diurnal courses (over all available site years) of (a-c) energy balance components and the energy balance ratio (EBR), (d-f) surface conductance $\left(G_{s}\right)$, and $(\mathrm{g}-\mathrm{i})$ the corresponding $G_{1}$ for the sites Fl-Hyy, AU-Tum, and FR-Pue. $G_{s}$ was calculated from Equation (2) for three hypothetical extreme cases with respect to the attribution of the residual of the energy balance closure to either $H, \lambda E$, or $A$, as well as for the Bowen ratio adjusted case. $G_{1}$ was estimated for all data in the respective half-hourly/hourly bin (Equation 3). Error bars indicate standard errors

on the time of day (Figure 5a-c) and most likely other conditions (e.g., turbulence intensity, Wilson et al., 2002; Leuning et al., 2012). The $y$-axis shows the ratio of the two most extreme estimates of $G_{s}$, which are given by $G_{s, \lambda E}$ (i.e., $G_{s}$ calculated from Equation (2) assuming that the residual is entirely attributed to $\lambda E$, i.e., $\lambda E=R_{\mathrm{n}}$ $(-G)-H$ ) and $G_{s, H}$ (i.e., assuming that the residual is entirely attributed to $H$ ). $G_{\mathrm{s}, \lambda \mathrm{E}}$ and $G_{\mathrm{s}, \mathrm{H}}$ are identical in case of a closed energy balance and yield the highest and lowest $G_{s}$ estimates if the EBR $<1$ and vice versa if the EBR $>1$. Any deviation in the EBR from 1 (positive or negative) causes the ratio of the two extreme estimates of $G_{s}$ to change exponentially with the EBR. The sensitivity of $G_{s, \lambda E} / G_{s}$, $\mathrm{H}$ to the EBR is similar for all sites (fitted lines in Figure $6 \mathrm{~b}$ ) and varies only slightly with VPD and other variables (results not shown). A typical value of $G_{s, \lambda E} / G_{s, H}$ is c. 2 for sites with an average EBR of c. 0.8 (as, for example, in Fl-Hyy) and exceeds 3 for sites with a poor energy balance closure (as, e.g., FR-Pue). It has to be noted that the ratio $G_{\mathrm{s}, \lambda \mathrm{E}} / G_{\mathrm{s}, \mathrm{H}}$ represents the maximum uncertainty in $G_{\mathrm{s}}$. This uncertainty is considerably lower if the residual is to large parts the result of an overestimation of $A$. The "true" $G_{s}$ and $G_{1}$ will most likely not reach the two extreme cases $G_{\mathrm{s}, \lambda \mathrm{E}}$ and $G_{\mathrm{s}, \mathrm{H}}$, but lie somewhere in between. Their exact values can only be determined if the values of $A, \lambda E$, and $H$ are correctly known.

\subsection{NEE partitioning algorithm}

The two algorithms ("daytime" (dt) and "nighttime" (nt)) that were used to partition NEE into its component fluxes GPP and $R_{\text {eco }}$ yielded similar average GPP values for the filtered daytime data within the growing season $\left(R^{2}=0.97\right.$; Figure $\left.7 a\right)$. Depending on the year, the nighttime method gave either higher or lower GPP estimates than the daytime method. Over all years, there was no consistent difference between the two methods across sites, but the nighttime approach tended to estimate higher GPP averages than the daytime method (Figure 7a). The patterns in GPP are clearly reflected in the $G_{1}$ values calculated using the two different GPP versions (Figure 7b). Higher estimates in GPP generally result in lower estimates of $G_{1}$ and vice versa. $G_{1}$ was further found to be relatively sensitive to GPP. On average, a change in GPP of 


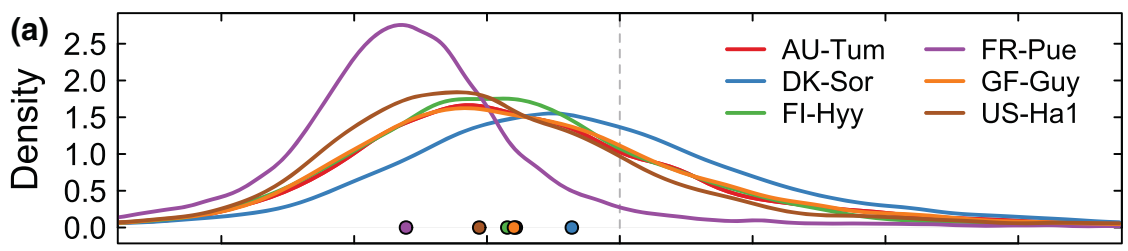

(b)
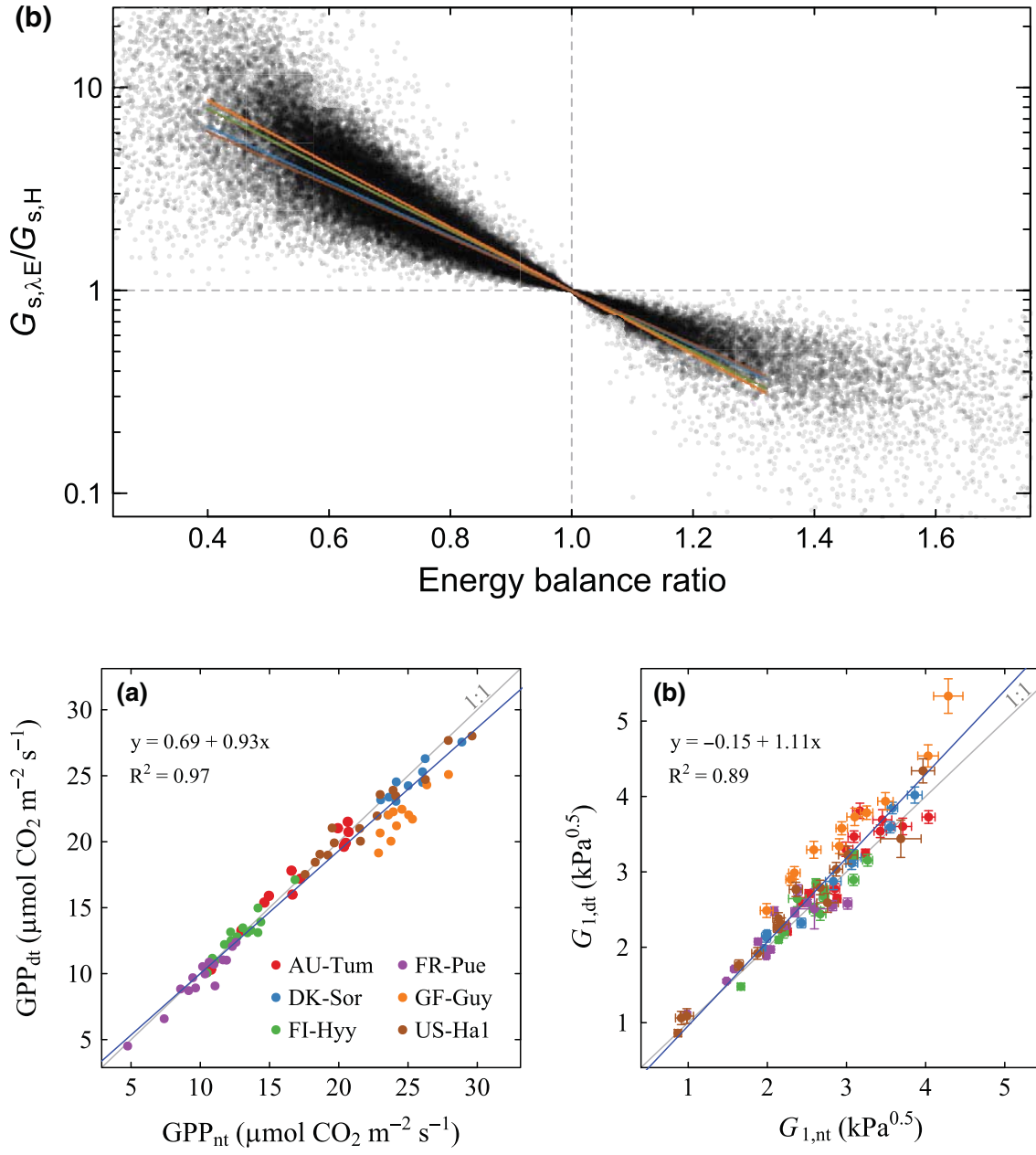

FIGURE 6 (a) Distribution of the halfhourly/hourly energy balance ratio (Equation 12) and (b) the maximum uncertainty in $G_{\mathrm{s}}$ (derived from the Penman-Monteith equation) resulting from an unclosed energy balance. The points in (a) indicate the median of the energy balance ratio. $G_{\mathrm{s}, \lambda \mathrm{E}}$ and $G_{\mathrm{s}, \mathrm{H}}$ in (b) are calculated from Equation (2) with $\lambda E=R_{\mathrm{n}}-G-H$ (or $\lambda E=R_{\mathrm{n}}-H$ if $G$ is unavailable) and $\lambda E$ as measured from the eddy covariance data, respectively. Lines in (b) are fitted with weighted least squares regression
FIGURE 7 Estimates of (a) mean growing season gross primary productivity (GPP) and (b) $G_{1}$ (Equation 3) with GPP derived from a daytime (dt; Lasslop et al., 2010) and nighttime (nt; Reichstein et al., 2005) partitioning approach of net ecosystem exchange (NEE). Data are filtered as described in Materials and methods. Blue lines indicate reduced major axis (RMA) regression fits
$1 \mu \mathrm{mol} \mathrm{m} \mathrm{m}^{-2} \mathrm{~s}^{-1}$ led to a change of $0.2 \mathrm{kPa}^{0.5}$ in $G_{1}$ across sites (Fig. S10).

\subsection{Within-canopy gradients}

The partial dependence plots in Figure 8 display the marginal effects of the relative contributions of the top and bottom layer $\left(G_{c, \text { layer }}\right)$ $G_{c, \text { total }} ; x$-axis) on the ecosystem-level $G_{1}$ as estimated from the EC data (y-axis). All subplots (except Figure $8 d$ (FR-Pue)) indicate that the contribution of the bottom layer $G_{c}$ to the total $G_{c}$ (black lines) increases along with the estimated $G_{1}$. In other words, under conditions when a comparatively large proportion of the $G_{1}$ signal comes from the lowest $1 / 3$ of the canopy, $G_{1}$ as estimated from the EC data (Equation 3) tends to be higher than when the lowest layer's contribution is small. As expected, the pattern is reverted for the contribution of the top layer (blue lines), in which case an increase in the relative contribution of the top layer is associated with a decrease in $G_{1}$. The two marginal effects are consistent across sites in that they imply higher $G_{1}$ values at the canopy bottom compared to the top, a behavior that is present at all sites except FR-Pue. An estimate of the within-canopy gradient was further made by fitting a linear model to the partial dependence plots, and extrapolating the fitted line to 1 , the hypothetical value at which the entire $G_{1}$ signal comes from the respective layer (dots in Figure 8). The ratio of the two values (representing the $G_{1}$ value of the bottom and top layer, respectively) is then an indication of the gradient within the canopy (denoted as "Ratio" in Figure 8). The gradients differed from site to site. We found a moderately high correlation $(r=.76)$ between the implied gradients and the degree of aerodynamic vegetation-atmosphere decoupling (results not shown). This may be an indication that relatively poorly coupled forests with tall and dense canopies (e.g., GF-Guy) are associated with higher within-canopy gradients. However, the low number of sites included in this study did not allow to investigate this aspect in more detail. The approach is further strongly affected by the effects of the energy balance non-closure on $G_{1}$, which are exceptionally critical for half-hourly/hourly data as used here (see Figure 5). At leaf 

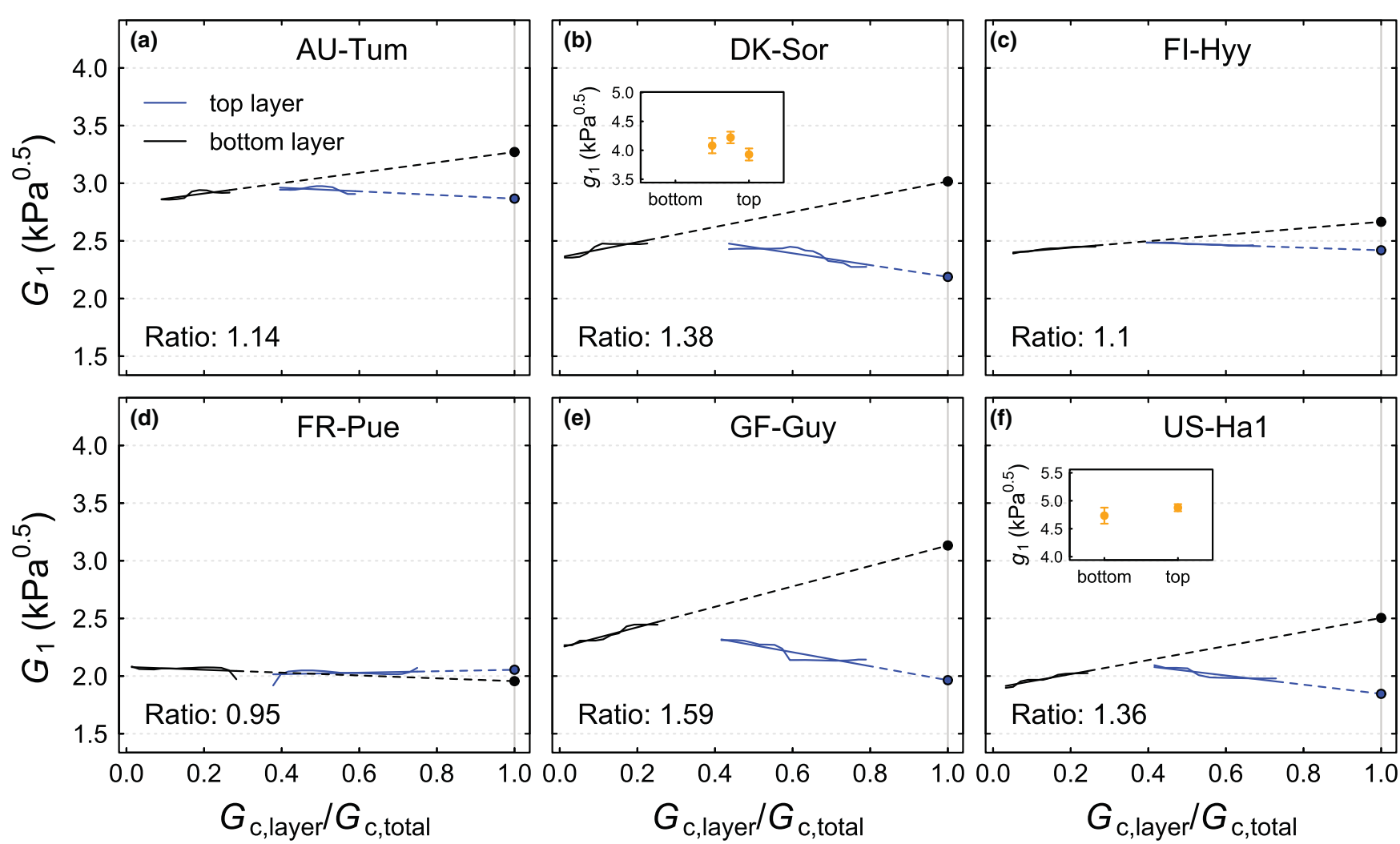

FIGURE 8 Partial dependence plots (solid lines) of the contribution of the top (blue line) and bottom layer (black line) (approximated as $G_{c}$, layer $/ G_{c, \text { total }}$ ) on the estimated $G_{1}$ (Equation 3). The straight lines represent the ordinary least squares fit to the partial dependences (solid) and their extrapolation to 1 (dashed). The ratio of the extrapolated values at 1 (i.e., $G_{1 \text {,bottom }} / G_{1, \text { top }}$ ) is indicated at the bottom left of each panel. Conditions where $\lambda E>A$ were excluded. Insets show $g_{1}$ estimates from available leaf gas exchange data at different positions in the canopy

level, $g_{1}$ estimates from different levels in the canopy did not indicate gradients at DK-Sor and US-Ha1 (insets in Figure 8b,f). It is important to note that $G_{1}$ gradients within the canopy can result from vertical gradients within plants of the same species or physiological differences between overstory and understory vegetation, information that can only be resolved with a more detailed knowledge on the vegetation at the site.

\section{4 | DISCUSSION}

In this study, we show that values of $G_{c}$ and the intrinsic WUE metric $G_{1}$ inferred from EC data are affected by confounding physical factors and methodological uncertainties (Table 2). We demonstrated that factors that are often overlooked in an ecophysiological context (e.g., energy balance non-closure, aerodynamic conductance) can be more critical for the accurate estimation of WUE than factors which are more commonly acknowledged (e.g., NEE partitioning algorithm, soil evaporation). The fact that observed discrepancies between the two data sources (Figure 1) could not be fully resolved may be attributed to the low level of scientific understanding (and corresponding high uncertainty) of the factors considered here (Table 2), or to issues of representativeness in the sense that species contributing to the ecosystem fluxes are not sampled in the same proportion at the leaf level (Table 1).
TABLE 2 Effects of the factors investigated in this study on the derived ecosystem-level intrinsic water-use efficiency measure $G_{1}$ and their uncertainties

\begin{tabular}{|c|c|c|c|}
\hline \multirow{2}{*}{$\begin{array}{l}\text { Factor } \\
\text { (1) Interception and } \\
\text { soil evaporation }\end{array}$} & \multicolumn{2}{|c|}{ Impact on $G_{1}(\%)$} & \multirow{2}{*}{$\begin{array}{l}\text { Uncertainty of } \\
\text { the effect } \\
\text { Medium-High }\end{array}$} \\
\hline & Medium & -10 to 50 & \\
\hline $\begin{array}{l}\text { (2) Aerodynamic } \\
\text { conductance }\end{array}$ & $\begin{array}{l}\text { Medium- } \\
\text { High }\end{array}$ & -10 to 70 & Low \\
\hline $\begin{array}{l}\text { (3) Meteorological } \\
\text { gradients canopy-air }\end{array}$ & Low & +0 to 15 & Medium \\
\hline $\begin{array}{l}\text { (4) Energy balance } \\
\text { non-closure }\end{array}$ & High & +0 to 400 & High \\
\hline (5) NEE partitioning & Low & \pm 0 to 20 & Medium \\
\hline $\begin{array}{l}\text { (6) Within-canopy } \\
\text { gradients in } g_{1}{ }^{a}\end{array}$ & Low & -0 to 20 & High \\
\hline
\end{tabular}

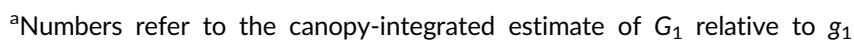
from the top third of the canopy only (as measured by leaf gas exchange).

\section{1 | Non-transpirational water fluxes}

The physiological interpretation of $G_{\mathrm{s}}$ is compromised if measured $\lambda E$ comprises substantial non-transpirational contributions from the soil or canopy interception, in which case $G_{\mathrm{s}}>G_{\mathrm{c}}$ (Kelliher, Leuning, Raupach, \& Schulze, 1995; Paw \& Meyers, 1989). The effects of 
non-transpirational $\lambda E$ on $G_{\mathrm{s}}$ can be assessed by either extrapolating $G_{\mathrm{s}}$ from dry periods to rainfall periods (e.g., Knohl \& Buchmann, 2005), or by excluding time periods following rainfall events, as was done here. Our results (Figure 2) underline the need to exclude time periods following precipitation in order to avoid an overestimation of $G_{c}$ and thus $G_{1}$. An additional exclusion of time periods affected by dew evaporation was found not to be necessary for the sites studied here, possibly because the overall contribution of dew to the total evapotranspiration is minor (see, e.g., Jacobs, Heusinkveld, Wichink Kruit, \& Berkowicz, 2006), or because the radiation threshold used here $\left(200 \mu \mathrm{mol} \mathrm{m} \mathrm{m}^{-2} \mathrm{~s}^{-1}\right)$ was sufficient to exclude major dew evaporation fluxes. Our Results confirm previous approaches in which the excluded time period is restricted to 2 days after rainfall (e.g., Beer et al., 2009; Ponton et al., 2006), a practical approach with regard to the tradeoff between physiologically meaningful $G_{s}$ estimates and a sufficient amount of data.

\subsection{Aerodynamic conductance and surface conditions}

The effect of $G_{a}$ on $G_{1}$ was found to be important for all ecosystems investigated here and is likely to be especially important for shortstatured (poorly coupled) vegetation. Figure $3 a$ demonstrates that the occasionally made assumption of a full aerodynamic coupling between the vegetation and the atmosphere (e.g., Beer et al., 2009; Groenendijk et al., 2011; Keenan et al., 2013) is, even for comparatively well coupled forests, not justified.

A simple estimate of $G_{a}$ (Equation 5 or similar) is often embedded in the PM equation (e.g., Blanken \& Black, 2004; Launiainen et al., 2016). This formulation only requires measurements of wind speed and $u_{*}$ and gives values similar to more complex approaches (Figure $3 b$ ).

A major difficulty in the derivation of $G_{a}$ at ecosystem level is the canopy boundary layer conductance $\left(G_{b}\right)$ (e.g., Verhoef, De Bruin, \& Van Den Hurk, 1997). Replacing the empirical $G_{\mathrm{b}}$ model (Equation 5) with a physically based formulation (Equation 6) (Massman, 1999; Su et al., 2001) considers a more comprehensive set of aerodynamically relevant properties of the ecosystem, but also introduces additional uncertainties. This is problematic due to the high sensitivity of this formulation (and that of others, e.g., McNaughton \& Van den Hurk, 1995) to the characteristic leaf dimension (Equations S2, S7, and S8); Figure 3b), information that is not always available and presumably highly variable at EC sites.

Using $G_{a}$ to infer the micrometeorology at the big-leaf surface as the physiologically relevant conditions (Grantz \& Meinzer, 1990) resulted in better model fits (Table S2), but had minor effects on the mean growing season $G_{1}$ values for the ecosystems investigated here. It appears unlikely that $G_{1}$ will be significantly affected by meteorological gradients within the canopy, as they have often been found to be even less pronounced than those between canopy and tower height (Linderson et al., 2012; Schurgers, Lagergren, Mölder, \& Lindroth, 2015). However, meteorological gradients are likely to be more relevant for more decoupled ecosystems (e.g., grasslands, croplands) but this also strongly depends on site-specific micrometeorological conditions (Magnani et al., 1998).

\subsection{Energy balance closure}

Energy balance non-closure, i.e., the phenomenon that the sum of the measured turbulent fluxes $H$ and $\lambda E$ is smaller than the available energy, is observed at most EC sites (Stoy et al., 2013; Wilson et al., 2002). Potential reasons for this issue are manifold (Foken, 2008; Leuning et al., 2012), but involve either an underestimation of the turbulent fluxes by EC measurement systems (due to, e.g., low-frequency losses resulting from mesoscale circulations; Foken, 2008; Stoy et al., 2013) or an overestimation of $A$, which arises predominantly when energy storage terms $(S)$ are neglected. Yet, not all components of $S$ can be readily determined. For example, the energy storage flux into and out of the aboveground biomass, which can sum up to approximately half of $S$ in forest ecosystems (Lindroth, Mölder, \& Lagergren, 2010), has to be estimated from biomass temperature, mass of the aboveground biomass as well as its heat capacity (see, e.g., Haverd, Cuntz, Leuning, \& Keith, 2007), information that is not available for most sites.

An unclosed energy balance affects the derivation of $G_{s}$ from the inverted PM equation, since the latter assumes the energy balance to be closed. Our results demonstrate that the inferred $G_{\mathrm{s}}$ is sensitive to a violation of this assumption, in agreement with the analysis for a grassland and a shrub ecosystem by Wohlfahrt et al. (2009). The error in $G_{s}$ that is made due to the energy balance nonclosure depends on which component of the energy balance is misrepresented in the measurements. An important implication is that the PM equation (Equation 2) implicitly assigns the residual entirely to $H$ and, therefore, underestimates (overestimates) $G_{s}$ when the $E B R<1(E B R>1) . G_{s}$ is less sensitive to errors in $S$, but highly sensitive to errors in $\lambda E$, with potential errors rising exponentially with a decline in the EBR (Figure 6b). In addition, an often observed diurnal cycle in the EBR also affects the diurnal courses of $G_{s}$ (Figure $5 d-f)$. Thus, both the magnitude and the temporal dynamics of $G_{s}$ are strongly confounded by (and dependent on) the degree of closure in the energy balance, which is problematic as the EBR is not expected to be a physiologically relevant driver of iWUE. The uncertainty in $G_{s}$ propagates to $G_{1}$ (Figure 5), which further depends on to what extent carbon fluxes are affected by the energy balance closure problem (see Barr, Morgenstern, Black, McCaughey, \& Nesic, 2006).

Our results call for accurate measurements of the surface energy storage terms ( $S$ in Equation 11) and their diurnal courses at EC sites. This information would help to constrain uncertainties in $G_{s}$ and ultimately allow application of flux correction procedures (Twine et al., 2000; "Bowen ratio adjusted" case in Figure 5), which "overcorrect" half-hourly/hourly turbulent fluxes if $S$ and/or $G$ are neglected, particularly in ecosystems with tall vegetation and high biomass. Careful consideration of all energy balance terms (as, e.g., in Blanken et al., 1997; Barr et al., 2006; Jacobs, Heusinkveld, \& Holtslag, 2008) and, where appropriate, adjustment of the turbulent 
fluxes are crucial for the derivation and physiological interpretation of EC-derived gas exchange characteristics on a sub-daily time scale.

\subsection{NEE partitioning and uncertainties across scales}

Figure 7 suggests that ecosystem-level $G_{1}$ is relatively robust to choices made on the partitioning approach, which is in line with the general good agreement between the two GPP products (Lasslop et al., 2010). Nonetheless, the high sensitivity of $G_{1}$ to GPP emphasizes the importance of correctly estimating GPP from EC data, which also relies on the use of a representative driving temperature for $R_{\text {eco }}$ (Lasslop et al., 2012). Also relevant for the direct comparison of $g_{1}$ at leaf and ecosystem levels are differences in the carbon uptake term used in Equations (1) and (3): net photosynthesis $\left(A_{n}\right)$ at the leaf level and GPP at the canopy level. The two have to be interpreted differently for two main reasons: (i) GPP estimated from flux partitioning algorithms integrates carboxylation $\left(V_{c}\right)$ minus photorespiration $\left(R_{\mathrm{p}}\right)$ and is thus not equivalent to (and to some extent larger than) net photosynthesis $\left(A_{\mathrm{n}}=V_{\mathrm{c}}-R_{\mathrm{p}}-R_{\mathrm{L}}\right)$ measured from leaflevel gas exchange. (ii) Leaf respiration in the dark $\left(R_{\mathrm{D}}\right)$ has been found to exceed that in daylight $\left(R_{\mathrm{L}}\right)$ (Atkin, Westbeek, Cambridge, Lambers, \& Pons, 1997; Brooks \& Farquhar, 1985), though a recent study suggests that this "Kok effect" could also be explained by changes in the chloroplastic $\mathrm{CO}_{2}$ concentration $\left(C_{c}\right)$ caused by a reduced mesophyll conductance at low light (Farquhar \& Busch, 2017), in which case $R_{\mathrm{D}}$ would not necessarily be down-regulated in the light. The consequence of a larger $R_{\mathrm{D}}$ compared to $R_{\mathrm{L}}$ would be that an extrapolation of nighttime respiration to daytime overestimates GPP (Wohlfahrt \& Gu, 2015). This effect is not considered in common flux partitioning approaches because it would require additional modeling efforts (e.g., light distribution within the canopy), knowledge of the fraction of leaf respiration to ecosystem respiration (Wohlfahrt, Bahn, Haslwanter, Newesely, \& Cernusca, 2005), and because the inhibition effect (i.e., the ratio $R_{\mathrm{L}} / R_{\mathrm{D}}$ ) is not well constrained (Niinemets, 2014). Both these issues lead to a lower estimate of $G_{1}$ at the ecosystem level compared to the leaf level. Estimates of canopy-scale $R_{\mathrm{L}}$ from our simulations amount to $3.4 \%$ of GPP on average across sites, whereas overestimation of GPP due to a possible light inhibition of $R_{\mathrm{D}}$ would be in the order of $15 \%$ (Janssens et al., 2001; Wehr et al., 2016; Wohlfahrt et al., 2005), indicating that the latter is the more relevant source of disagreement between across-scale estimates of $G_{1}$, but clearly a better process understanding is needed (Farquhar \& Busch, 2017).

\section{5 | Within-canopy gradients}

Pronounced canopy gradients of $G_{1}$ as estimated in this study for some sites (Figure 8) were not supported by leaf-level measurements at DK-Sor and US-Ha1. However, canopy gradients were in agreement with several observational studies reporting a lower iWUE (corresponding to a higher $g_{1}$ ) in the understory both across (Domingues, Martinelli, \& Ehleringer, 2007) and within species (Sellin,
Eensalu, \& Niglas, 2010), a pattern that results from the maintenance of a relatively high $g_{\mathrm{s}}$ at the canopy bottom compared to the top (Chazdon, 1988). As EC measurements integrate $G_{1}$ over the existing canopy gradients whereas leaf measurements do not, the former are expected to give higher values than the latter (if taken at the top of the canopy). This effect depends both on the gradient itself as well as the relative flux contribution from the different layers. Our results indicate that within-canopy gradients of $g_{1}$ are site- and possibly species-specific, highlighting the need for additional leaf-level measurements at different levels in the canopy, as well as a more comprehensive characterization of the understory vegetation and its contribution to total ecosystem fluxes.

\subsection{Recommendations for future studies}

In this study, we aimed to derive a physiologically meaningful WUE metric $\left(G_{1}\right)$ from EC data that can be used in modeling and for the characterization of the physiological control of ecosystem water-carbon coupling. We were limited to forest sites in this study by the availability of leaf gas exchange data, but it would be useful to extend this analysis to non-forest sites or to include carbon isotope data as an independent dataset (as, e.g., in Medlyn et al. (2017)). We demonstrate that EC-derived $G_{\mathrm{s}}$ and $G_{1}$ are strongly affected by (i) confounding physical factors and (ii) methodological uncertainties, and are subject to (iii) conceptual differences to leaf-level estimates. Ignoring these factors compromises the ecophysiological interpretation of EC-derived vegetation gas exchange characteristics as well as their direct comparison to leaf-level estimates. Based on our analysis, we have the following recommendations for the calculation of $G_{1}$ :

- Exclusion of time periods for at least $24 \mathrm{hr}$ after rainfall.

- The assumption $G_{a}=\infty$ is inappropriate; the use of physically based $G_{a}$ models is only recommended if site-specific aerodynamic properties are known.

- The derivation of canopy surface meteorology (e.g., VPD) is meaningful, but of secondary importance for average growing season values.

- Critical evaluation and (if appropriate) correction of all energy balance terms is pivotal.

- Both daytime and nighttime NEE partitioning algorithms can be used for WUE studies.

- EC data should be complemented by physiological (leaf level) and meteorological measurements made at different levels in the canopy.

\section{ACKNOWLEDGEMENTS}

This work used eddy covariance data acquired and shared by the FLUXNET community, including the following networks: AmeriFlux, AfriFlux, AsiaFlux, CarboAfrica, CarboEuropelP, Carboltaly, CarboMont, ChinaFlux, Fluxnet-Canada, GreenGrass, ICOS, KoFlux, LBA, NECC, OzFlux-TERN, TCOS-Siberia, and USCCC. The FLUXNET eddy covariance data processing and harmonization were carried out 
by the European Fluxes Database Cluster, AmeriFlux Management Project, and Fluxdata project of FLUXNET, with the support of CDIAC and ICOS Ecosystem Thematic Center, and the OzFlux, ChinaFlux, and AsiaFlux offices. We thank Prof. D. Baldocchi for constructive comments on the topic. SZ was supported by the European Research Council (ERC) under the European Union's Horizon 2020 research and innovation program (grant agreement no. 647204; QUINCY).

\section{REFERENCES}

Anderson, M. C., Kustas, W. P., \& Norman, J. M. (2003). Upscaling and downscaling - A regional view of the soil-plant-atmosphere continuum. Agronomy Journal, 95, 1408-1423.

Atkin, O. K., Westbeek, M. H., Cambridge, M. L., Lambers, H., \& Pons, T. L. (1997). Leaf respiration in light and darkness (a comparison of slow-and fast-growing Poa species). Plant Physiology, 113, 961-965.

Aubinet, M., Grelle, A., Ibrom, A., Rannik, Ü., Moncrieff, J., Foken, T., .. Vesala, T. (1999). Estimates of the annual net carbon and water exchange of forests: The EUROFLUX methodology. Advances in Ecological Research, 30, 113-175.

Ball, J. T., Woodrow, I. E., \& Berry, J. A. (1987). A model predicting stomatal conductance and its contribution to the control of photosynthesis under different environmental conditions. In J. Biggins (Ed.), Progress in photosynthesis research (pp. 221-224). Dordrecht, the Netherlands: Martinus Nijhoff Publishers.

Barnard, D., \& Bauerle, W. (2013). The implications of minimum stomatal conductance on modeling water flux in forest canopies. Journal of Geophysical Research: Biogeosciences, 118, 1322-1333.

Barr, A., Morgenstern, K., Black, T., McCaughey, J., \& Nesic, Z. (2006). Surface energy balance closure by the eddy-covariance method above three boreal forest stands and implications for the measurement of the $\mathrm{CO}_{2}$ flux. Agricultural and Forest Meteorology, 140, 322-337.

Bassow, S., \& Bazzaz, F. (1997). Intra-and inter-specific variation in canopy photosynthesis in a mixed deciduous forest. Oecologia, 109, 507-515.

Beer, C., Ciais, P., Reichstein, M., Baldocchi, D., Law, B. E., Papale, D., ... Wohlfahrt, G. (2009). Temporal and among-site variability of inherent water use efficiency at the ecosystem level. Global Biogeochemical Cycles, 23, GB2018.

Blanken, P., \& Black, T. (2004). The canopy conductance of a boreal aspen forest, Prince Albert National Park, Canada. Hydrological Processes, 18, 1561-1578.

Blanken, P., Black, T., Yang, P., Neumann, H. H., Nesic, Z., Staebler, R., ... Lee, $X$. (1997). Energy balance and canopy conductance of a boreal aspen forest: Partitioning overstory and understory components. Journal of Geophysical Research, 102, 915-927.

Bonal, D., Bosc, A., Ponton, S., Baldocchi, D., Law, B. E., Papale, D., ... Wohlfahrt, G. (2008). Impact of severe dry season on net ecosystem exchange in the Neotropical rainforest of French Guiana. Global Change Biology, 14, 1917-1933.

Brooks, A., \& Farquhar, G. (1985). Effect of temperature on the $\mathrm{CO}_{2} / \mathrm{O}_{2}$ specificity of ribulose-1,5-bisphosphate carboxylase/oxygenase and the rate of respiration in the light. Planta, 165, 397-406.
Chazdon, R. L. (1988). Sunflecks and their importance to forest understorey plants. Advances in Ecological Research, 18, 1-63.

de Pury, D., \& Farquhar, G. (1997). Simple scaling of photosynthesis from leaves to canopies without the errors of big-leaf models. Plant, Cell and Environment, 20, 537-557.

Denmead, O., Dunin, F., Wong, S., \& Greenwood, E. (1993). Measuring water use efficiency of eucalypt trees with chambers and micrometeorological techniques. Journal of Hydrology, 150, 649-664.

Desai, A. R., Richardson, A. D., Moffat, A. M., Kattge, J., Hollinger, D. Y., Barr, A., ... Stauch, V. J. (2008). Cross-site evaluation of eddy covariance GPP and RE decomposition techniques. Agricultural and Forest Meteorology, 148, 821-838.

Domingues, T. F., Martinelli, L. A., \& Ehleringer, J. R. (2007). Ecophysiological traits of plant functional groups in forest and pasture ecosystems from eastern Amazonia, Brazil. Plant Ecology, 193, 101112.

Dubbert, M., Piayda, A., Cuntz, M., Correia, A. C., Costa e Silva, F., Pereira, J. S., \& Werner, C. (2014). Stable oxygen isotope and flux partitioning demonstrates understory of an oak savanna contributes up to half of ecosystem carbon and water exchange. Frontiers in Plant Science, 5, 530 .

Farquhar, G. D., \& Busch, F. A. (2017). Changes in the chloroplastic $\mathrm{CO}_{2}$ concentration explain much of the observed Kok effect: A model. New Phytologist, 214, 570-584.

Farquhar, G., Hubick, K., Condon, A., \& Richards, R. (1989). Carbon isotope fractionation and plant water-use efficiency. In P. Rundel, J. R. Ehleringer \& K. Nagy (Eds.), Stable isotopes in ecological research (pp. 21-40). New York, NY: Springer.

Farquhar, G., von Caemmerer, S., \& Berry, J. (1980). A biochemical model of photosynthetic $\mathrm{CO}_{2}$ assimilation in leaves of $\mathrm{C} 3$ species. Planta, $149,78-90$.

Foken, T. (2008). The energy balance closure problem: An overview. Ecological Applications, 18, 1351-1367.

Grantz, D., \& Meinzer, F. (1990). Stomatal response to humidity in a sugarcane field: Simultaneous porometric and micrometeorological measurements. Plant, Cell and Environment, 13, 27-37.

Groenendijk, M., Dolman, A., Ammann, C., Arneth, A., Cescatti, A., Dragoni, D., ... Wohlfahrt, G. (2011). Seasonal variation of photosynthetic model parameters and leaf area index from global Fluxnet eddy covariance data. Journal of Geophysical Research: Biogeosciences, 116, G04027.

Haverd, V., Cuntz, M., Leuning, R., \& Keith, H. (2007). Air and biomass heat storage fluxes in a forest canopy: Calculation within a soil vegetation atmosphere transfer model. Agricultural and Forest Meteorology, 147, 125-139.

Ito, A., \& Inatomi, M. (2012). Water-use efficiency of the terrestrial biosphere: A model analysis focusing on interactions between the global carbon and water cycles. Journal of Hydrometeorology, 13, 681-694.

Jacobs, A. F., Heusinkveld, B. G., \& Holtslag, A. A. (2008). Towards closing the surface energy budget of a mid-latitude grassland. BoundaryLayer Meteorology, 126, 125-136.

Jacobs, A. F., Heusinkveld, B. G., Wichink Kruit, R. J., \& Berkowicz, S. M. (2006). Contribution of dew to the water budget of a grassland area in the Netherlands. Water Resources Research, 42, 1-8.

Janssens, I., Lankreijer, H., Matteucci, G., Kowalski, A. S., Buchmann, N., Epron, D., ... Valentini, R. (2001). Productivity overshadows temperature in determining soil and ecosystem respiration across European forests. Global Change Biology, 7, 269-278.

Jarvis, P. G., \& McNaughton, K. (1986). Stomatal control of transpiration: Scaling up from leaf to region. Advances in Ecological Research, 15, 149.

Keenan, T. F., Hollinger, D. Y., Bohrer, G., Dragoni, D., Munger, J. W., Schmid, H. P., \& Richardson, A. D. (2013). Increase in forest wateruse efficiency as atmospheric carbon dioxide concentrations rise. Nature, 499, 324-327. 
Kelliher, F., Leuning, R., Raupach, M., \& Schulze, E.-D. (1995). Maximum conductances for evaporation from global vegetation types. Agricultural and Forest Meteorology, 73, 1-16.

Kelliher, F., Lloyd, J., Arneth, A., Byers, J. N., McSeveny, T. M., Milukova, I., ... Schulze, E.-D. (1998). Evaporation from a central Siberian pine forest. Journal of Hydrology, 205, 279-296.

Knauer, J., Zaehle, S., Reichstein, M., Medlyn, B. E., Forkel, M., Hagemann, S., \& Werner, C. (2017). The response of ecosystem water-use efficiency to rising atmospheric $\mathrm{CO}_{2}$ concentrations: sensitivity and largescale biogeochemical implications. New Phytologist, 213, 1654-1666.

Knohl, A., \& Buchmann, N. (2005). Partitioning the net $\mathrm{CO}_{2}$ flux of a deciduous forest into respiration and assimilation using stable carbon isotopes. Global Biogeochemical Cycles, 19, GB4008.

Kolari, P., Lappalainen, H. K., Hänninen, H., \& Hari, P. (2007). Relationship between temperature and the seasonal course of photosynthesis in Scots pine at northern timberline and in southern boreal zone. Tellus Series B, 59, 542-552.

Lasslop, G., Migliavacca, M., Bohrer, G., Reichstein, M., Bahn, M., Ibrom, A., ... Cescatti, A. (2012). On the choice of the driving temperature for eddy-covariance carbon dioxide flux partitioning. Biogeosciences, 9, 5243-5259.

Lasslop, G., Reichstein, M., Papale, D., Richardson, A. D., Arneth, A., Barr, A., ... Wohlfahrt, G. (2010). Separation of net ecosystem exchange into assimilation and respiration using a light response curve approach: Critical issues and global evaluation. Global Change Biology, 16, 187-208.

Launiainen, S., Katul, G. G., Kolari, P., Vesala, T., \& Hari, P. (2011). Empirical and optimal stomatal controls on leaf and ecosystem level $\mathrm{CO}_{2}$ and $\mathrm{H}_{2} \mathrm{O}$ exchange rates. Agricultural and Forest Meteorology, 151, 1672-1689.

Launiainen, S., Katul, G. G., Kolari, P., Lindroth, A., Lohila, A., Aurela, M., ... Vesala, T. (2016). Do the energy fluxes and surface conductance of boreal coniferous forests in Europe scale with leaf area? Global Change Biology, 22, 4096-4113.

Leuning, R. (1995). A critical appraisal of a combined stomatal-photosynthesis model for C3 plants. Plant, Cell and Environment, 18, 339-355.

Leuning, R., Cleugh, H. A., Zegelin, S. J., \& Hughes, D. (2005). Carbon and water fluxes over a temperate Eucalyptus forest and a tropical wet/dry savanna in Australia: Measurements and comparison with MODIS remote sensing estimates. Agricultural and Forest Meteorology, 129, 151-173.

Leuning, R., Van Gorsel, E., Massman, W. J., \& Isaac, P. R. (2012). Reflections on the surface energy imbalance problem. Agricultural and Forest Meteorology, 156, 65-74.

Lin, Y.-S., Medlyn, B. E., Duursma, R. A., Prentice, I. C., Wang, H., Baig, S., ... Wingate, L. (2015). Optimal stomatal behaviour around the world. Nature Climate Change, 5, 459-464.

Linderson, M.-L., Mikkelsen, T., Ibrom, A., Lindroth, A., Ro-Poulsen, H., \& Pilegaard, K. (2012). Up-scaling of water use efficiency from leaf to canopy as based on leaf gas exchange relationships and the modeled in-canopy light distribution. Agricultural and Forest Meteorology, 152, 201-211.

Lindroth, A., Mölder, M., \& Lagergren, F. (2010). Heat storage in forest biomass improves energy balance closure. Biogeosciences, 7, 301 313.

Lloyd, J., \& Taylor, J. (1994). On the temperature dependence of soil respiration. Functional Ecology, 8, 315-323.

Long, S., \& Bernacchi, C. (2003). Gas exchange measurements, what can they tell us about the underlying limitations to photosynthesis? Procedures and sources of error. Journal of Experimental Botany, 54, 2393-2401.

Maechler, M., Rousseeuw, P., Croux, C. Todorov, V., Ruckstuhl, A., Salibian-Barrera, M., ... di Palma, A. M. (2016). robustbase: Basic Robust Statistics R package version 0.92-7. URL http://CRAN.Rproject.org/ package=robustbase.
Magnani, F., Leonardi, S., Tognetti, R., Grace, J., \& Borghetti, M. (1998). Modelling the surface conductance of a broad-leaf canopy: Effects of partial decoupling from the atmosphere. Plant, Cell and Environment, $21,867-879$.

Martin-StPaul, N. K., Limousin, J.-M., Rodríguez-Calcerrada, J., Ruffault, J., Rambal, S., Letts, M. G., \& Misson, L. (2012). Photosynthetic sensitivity to drought varies among populations of Quercus ilex along a rainfall gradient. Functional Plant Biology, 39, 25-37.

Massman, W. (1999). A model study of $\mathrm{kB}_{\mathrm{H}}{ }^{-1}$ for vegetated surfaces using 'localized near-field' Lagrangian theory. Journal of Hydrology, 223, 27-43.

McNaughton, K., \& Van den Hurk, B. (1995). A 'Lagrangian' revision of the resistors in the two-layer model for calculating the energy budget of a plant canopy. Boundary-Layer Meteorology, 74, 261-288.

Medlyn, B. E., De Kauwe, M., Lin, Y.-S., Knauer, J., Duursma, R. A., Williams, C. A., ... Wingate, L. (2017). How do leaf and ecosystem measures of water-use efficiency compare? New Phytologist.

Medlyn, B. E., Duursma, R. A., Eamus, D., Ellsworth, D. S., Prentice, C. I., Barton, C. V. M., ... Wingate, L. (2011). Reconciling the optimal and empirical approaches to modelling stomatal conductance. Global Change Biology, 17, 2134-2144.

Medlyn, B. E., Pepper, D. A., O'Grady, A. P., \& Keith, H. (2007). Linking leaf and tree water use with an individual-tree model. Tree Physiology, 27, 1687-1699.

Monteith, J. (1965). Evaporation and environment. In G. E. Fogg (Ed.), The state and movement of water in living organisms (pp. 205-234). Cambridge: Cambridge University Press 19th Symp. Soc. Exp. Biol.

Niinemets, Ü. (2014). Improving modeling of the 'dark part' of canopy carbon gain. Tree Physiology, 34, 557-563.

Osmond, C., Björkman, O., \& Anderson, D. (1980). Physiological processes in plant ecology. Berlin: Springer.

Papale, D., Reichstein, M., Aubinet, M., Canfora, E., Bernhofer, C., Kutsch, W., ... Yakir, D. (2006). Towards a standardized processing of Net Ecosystem Exchange measured with eddy covariance technique: algorithms and uncertainty estimation. Biogeosciences, 3, 571-583.

Paw, U. K. T., \& Meyers, T. P. (1989). Investigations with a higher-order canopy turbulence model into mean source-sink levels and bulk canopy resistances. Agricultural and Forest Meteorology, 47, 259-271.

Pilegaard, K., Ibrom, A., Courtney, M. S., Hummelshøj, P., \& Jensen, N. O. (2011). Increasing net $\mathrm{CO}_{2}$ uptake by a Danish beech forest during the period from 1996 to 2009. Agricultural and Forest Meteorology, 151, 934-946.

Ponton, S., Flanagan, L. B., Alstad, K. P., Johnson, B. G., Morgenstern, K., Kljun, N., ... Barr, A. G. (2006). Comparison of ecosystem water-use efficiency among Douglas-fir forest, aspen forest and grassland using eddy covariance and carbon isotope techniques. Global Change Biology, 12, 294-310.

Rambal, S., Ourcival, J.-M., Joffre, R., Mouillot, F., Nouvellon, Y., Reichstein, M., \& Rocheteau, A. (2003). Drought controls over conductance and assimilation of a Mediterranean evergreen ecosystem: Scaling from leaf to canopy. Global Change Biology, 9, 1813-1824.

Raupach, M., \& Finnigan, J. (1988). 'Single-layer models of evaporation from plant canopies are incorrect but useful, whereas multilayer models are correct but useless': Discuss. Functional Plant Biology, 15, 705-716.

Reichstein, M., Bahn, M., Mahecha, M. D., Kattge, J., \& Baldocchi, D. D. (2014). Linking plant and ecosystem functional biogeography. Proceedings of the National Academy of Sciences, 111, 13697-13702.

Reichstein, M., Falge, E., Baldocchi, D., Papale, D., Valentini, R., Aubinet, M., ... Yakir, D. (2005). On the separation of net ecosystem exchange into assimilation and ecosystem respiration: Review and improved algorithm. Global Change Biology, 11, 1424-1439.

Schulze, E.-D., \& Hall, A. (1982). Stomatal responses, water loss and $\mathrm{CO}_{2}$ assimilation rates of plants in contrasting environments. In O. Lange, 
P. Nobel, C. Osmond \& H. Ziegler (Eds.), Physiological plant ecology II (pp. 181-230). Berlin: Springer.

Schurgers, G., Lagergren, F., Mölder, M., \& Lindroth, A. (2015). The importance of micrometeorological variations for photosynthesis and transpiration in a boreal coniferous forest. Biogeosciences, 12, 237 256.

Sellin, A., Eensalu, E., \& Niglas, A. (2010). Is distribution of hydraulic constraints within tree crowns reflected in photosynthetic water-use efficiency? An example of Betula pendula. Ecological Research, 25, 173-183.

Shuttleworth, W. J., \& Wallace, J. (1985). Evaporation from sparse cropsan energy combination theory. Quarterly Journal of the Royal Meteorological Society, 111, 839-855.

Spitters, C. (1986). Separating the diffuse and direct component of global radiation and its implications for modeling canopy photosynthesis Part II. Calculation of canopy photosynthesis. Agricultural and Forest Meteorology, 38, 231-242.

Stoy, P. C., Mauder, M., Foken, T., Marcolla, B., Boegh, E., Ibrom, A., ... Varlagin, A. (2013). A data-driven analysis of energy balance closure across FLUXNET research sites: The role of landscape scale heterogeneity. Agricultural and Forest Meteorology, 171, 137-152.

Su, Z., Schmugge, T., Kustas, W., \& Massman, W. (2001). An evaluation of two models for estimation of the roughness height for heat transfer between the land surface and the atmosphere. Journal of Applied Meteorology, 40, 1933-1951.

Thom, A. (1972). Momentum, mass and heat exchange of vegetation. Quarterly Journal of the Royal Meteorological Society, 98, 124-134.

Twine, T. E., Kustas, W., Norman, J., Cook, D. R., Houser, P. R., Meyers, T. P., ... Wesely, M. L. (2000). Correcting eddy-covariance flux underestimates over a grassland. Agricultural and Forest Meteorology, 103, 279-300.

Urbanski, S., Barford, C., Wofsy, S., Kucharik, C., Pyle, E., Budney, J., ... Munger, J. W. (2007). Factors controlling $\mathrm{CO}_{2}$ exchange on timescales from hourly to decadal at Harvard Forest. Journal of Geophysical Research: Biogeosciences, 112, G02020.

van Dijk, A. I., Gash, J. H., van Gorsel, E., Blanken, P. D., Cescatti, A., Emmel, C., ... Wohlfahrt, G. (2015). Rainfall interception and the coupled surface water and energy balance. Agricultural and Forest Meteorology, 214, 402-415.

Verhoef, A., De Bruin, H., \& Van Den Hurk, B. (1997). Some practical notes on the parameter $\mathrm{kB}^{-1}$ for sparse vegetation. Journal of Applied Meteorology, 36, 560-572.
Verma, S. (1989). Aerodynamic resistances to transfers of heat, mass and momentum. In A. Black, D. Spittlehouse, M. Novak \& D. Price (Eds.), Estimation of areal evapotranspiration (pp. 13-20). Wallingford, UK: International Association of Hydrological Sciences IAHS Publication No. 177.

Vesala, T., Suni, T., Rannik, U., Keronen, P., Markkanen, T., Sevanto, S., ... Hari, P. (2005). Effect of thinning on surface fluxes in a boreal forest. Global Biogeochemical Cycles, 19, GB2001.

Wehr, R., Munger, J., McManus, J., Nelson, D. D., Zahniser, M. S., Davidson, E. A., ... Saleska, S. R. (2016). Seasonality of temperate forest photosynthesis and daytime respiration. Nature, 534, 680683.

Wilson, K., Goldstein, A., Falge, E., Aubinet, M., Baldocchi, D., Berbigier, P., ... Verma, S. (2002). Energy balance closure at FLUXNET sites. Agricultural and Forest Meteorology, 113, 223-243.

Wohlfahrt, G., Bahn, M., Haslwanter, A., Newesely, C., \& Cernusca, A. (2005). Estimation of daytime ecosystem respiration to determine gross primary production of a mountain meadow. Agricultural and Forest Meteorology, 130, 13-25.

Wohlfahrt, G., \& Gu, L. (2015). The many meanings of gross photosynthesis and their implication for photosynthesis research from leaf to globe. Plant, Cell and Environment, 38, 2500-2507.

Wohlfahrt, G., Haslwanter, A., Hörtnagl, L., Jasoni, R. L., Fenstermaker, L. F., Arnone, J. A., \& Hammerle, A. (2009). On the consequences of the energy imbalance for calculating surface conductance to water vapour. Agricultural and Forest Meteorology, 149, 1556-1559. 


\section{Supporting Information for Knauer et al. - Global Change Biology}

Article title: "Towards physiologically meaningful water-use efficiency estimates from eddy covariance data"

Authors: Jürgen Knauer*, Sönke Zaehle, Belinda E. Medlyn, Markus Reichstein, Christopher A. Williams, Mirco Migliavacca, Martin G. De Kauwe, Christiane Werner, Claudia Keitel, Pasi Kolari, Jean-Marc Limousin, Maj-Lena Linderson

*corresponding author (jknauer@bgc-jena.mpg.de)

\section{A. Physically-based canopy boundary layer conductance model}

The non-turbulent component of $G_{\mathrm{a}}$ is often expressed as the $k B^{-1}$ parameter (Verhoef et al., 1997; Massman, 1999), which is related to the boundary layer resistance $\left(R_{\mathrm{b}}\right)$ as follows (e.g. Verma, 1989):

$$
R_{\mathrm{b}}=\frac{k B^{-1}}{k u_{*}}
$$

where $k$ is the von-Kármán constant $(0.41), u_{*}$ is the friction velocity $\left(\mathrm{m} \mathrm{s}^{-1}\right)$, and $B^{-1}$ is the inverse Stanton number (Owen \& Thomson, 1963). The $\mathrm{kB}^{-1}$ model used in this study (second term in Eq. (6)) was originally developed by Massman (1999), and simplified by Su et al. (2001):

$$
k B^{-1}=\frac{k C_{\mathrm{d}}}{4 C_{t} \frac{u_{*}}{u\left(z_{\mathrm{h}}\right)}} f_{c}^{2}+k B_{s}^{-1}\left(1-f_{c}\right)^{2}
$$

where $C_{\mathrm{d}}$ is a foliage drag coefficient, assumed constant with a value of 0.2 (Massman, 1999), $C_{\mathrm{t}}$ is the heat transfer coefficient of the leaf, $u\left(z_{\mathrm{h}}\right)$ is the wind speed at canopy height $\left(\mathrm{m} \mathrm{s}^{-1}\right), f_{c}$ is fractional canopy cover, and $B_{s}^{-1}$ is the inverse Stanton number for bare soil surface (Su et al., 2001). $f_{c}$ was calculated from LAI for all sites:

$$
f_{\mathrm{c}}=(1-\exp (-0.5 \mathrm{LAI}))
$$

The $k B^{-1}$ value for bare soil surface $\left(k B_{S}^{-1}\right)$ is given by: 


$$
k B_{S}^{-1}=2.46 * \mathrm{Re}^{0.25}-\log (7.4)
$$

where Re is the Reynolds number for bare soil $\operatorname{Re}=h_{\mathrm{s}} u_{*} / v$ (Su et al., 2001), where $h_{\mathrm{s}}$ is the roughness length of the soil, set to $0.01 \mathrm{~m}$, and $v$ is the kinematic viscosity of air $\left(\mathrm{m}^{2} \mathrm{~s}^{-1}\right)$.Wind speed at canopy height $u\left(z_{\mathrm{h}}\right)$ was calculated from the logarithmic wind profile equation:

$$
u\left(z_{\mathrm{h}}\right)=\frac{u_{*}}{k}\left(\ln \left[\frac{\left(z_{\mathrm{h}}-d\right)}{z_{0 \mathrm{~m}}}\right]-\psi_{\mathrm{m}}\right)
$$

where $z_{\mathrm{r}}$ is measurement height $(\mathrm{m})$ and $\psi_{\mathrm{m}}$ the integrated stability correction function for momentum (Paulson, 1970), which is a function of the stability parameter $\zeta\left(\zeta=\left(z_{\mathrm{r}}-d\right) / L\right)$, where $L$ is the Monin-Obukhov length. The zero-plane displacement height $d(\mathrm{~m})$ was fixed as a constant fraction of the canopy height $\left(d=0.7 z_{\mathrm{h}}\right)$, and the roughness length for momentum $z_{0 \mathrm{~m}}$ (m) was estimated from the following relation:

$$
z_{0 \mathrm{~m}}=\left(z_{\mathrm{r}}-d\right) \exp \left(-k u / u_{*}-\psi_{\mathrm{m}}\right)
$$

Note that $z_{0 \mathrm{~m}}$ as estimated from Eq. (S6) implicitly accounts for changes in $z_{\mathrm{r}}$ and/or $d$ (along with e.g. an increase in canopy height), for which information was not available on an annual basis. As a consequence, $z_{0 \mathrm{~m}}$ in this study has to be interpreted as an effective parameter, integrating any changes in the aerodynamic properties of the ecosystem.

The heat transfer coefficient $C_{\mathrm{t}}$ is given by:

$$
C_{\mathrm{t}}=\operatorname{Pr}^{-2 / 3} \operatorname{Re}_{\mathrm{h}}^{-1 / 2} N
$$

where $N$ is the number of leaf sides participating in heat transfer (Massman, 1999), Pr is the Prandtl number (0.71), and $\operatorname{Re}_{\mathrm{h}}$ is the Reynolds number, defined as:

$$
\operatorname{Re}_{\mathrm{h}}=D_{\mathrm{l}} u / v
$$

where $D_{\mathrm{l}}$ is the characteristic leaf dimension (m), which was approximated by the geometric mean of the average leaf width and leaf length of the dominant species at the site (Table S1). $N$ in Eq. S7 was set to 2 for both water vapor and heat, thus assuming that both $k B^{-1}$ and $R_{\mathrm{b}}$ are equal for the two scalars. This is one assumption made in the PM equation (Eq. (2)), which was supported experimentally (Verma, 1989). 


\section{B. Random forest model}

The random forest algorithm is implemented in $\mathrm{R}$ using the randomForest package (Liaw \& Wiener, 2002). The following regression model was constructed:

$$
G_{1} \sim \mathrm{EBR}_{\text {halfhourly }}+\lambda E+\mathrm{PPFD}+T_{0}+G_{\mathrm{a}, \mathrm{empGb}}+\mathrm{DOY}+\text { hour }+G_{\mathrm{c}, \text { layer }} / G_{\mathrm{c}, \text { tot }}
$$

where DOY is day of year. The focus was on the relationship between $G_{1}$ and the fraction of $G_{\mathrm{c}}$ coming from a certain layer (i.e. $G_{c, \text { layer }} / G_{\text {c,tot }}$ as a proxy for the contribution of $G_{1 \text {,layer }}$ to total $G_{1}$ ). The marginal effect of $G_{c, \text { layer }} / G_{c, \text { tot }}$ on $G_{1}$ was calculated with the function partialPlot(). 


\section{Tables}

Table S1: Basic observed and calculated aerodynamic properties of the sites investigated in this study. ( $z_{\mathrm{h}}=$ mean canopy height; $\zeta=$ stability parameter; $D_{\mathrm{l}}=$ characteristic leaf dimension; $R_{\mathrm{aM}}=$ aerodynamic resistance for momentum; $R_{\mathrm{b}, \mathrm{empGb}}=$ canopy boundary layer resistance for heat, calculated according to Thom (1972); $R_{\mathrm{b}, \mathrm{physGb}}=$ canopy boundary layer resistance for heat, calculated according to Su et al. (2001); $k B^{-1}$,physGb $=k B^{-1}$ parameter, calculated according to Su et al. (2001); $R_{\mathrm{a}, \mathrm{mpGb}}=$ total aerodynamic resistance for heat, calculated according to Eq. 5 in the main manuscript; $R_{\text {a,physGb }}=$ total aerodynamic resistance for heat, calculated according to Eq. 6 in the main manuscript). Shown are median values over all site years. Data were filtered as described in the Materials and methods section.

\begin{tabular}{lccccccccc} 
Site & $\begin{array}{c}\mathrm{z}_{\mathrm{h}} \\
(\mathrm{m})\end{array}$ & $\zeta$ & $\begin{array}{c}D_{\mathrm{l}} \\
(\mathrm{m})\end{array}$ & $\begin{array}{c}R_{\mathrm{aM}} \\
\left(\mathrm{s} \mathrm{m}^{-1}\right)\end{array}$ & $\begin{array}{c}R_{\mathrm{b}, \text { empGb }} \\
\left(\mathrm{s} \mathrm{m}^{-1}\right)\end{array}$ & $\begin{array}{c}R_{\mathrm{b}, \text { physGb }} \\
\left(\mathrm{s} \mathrm{m}^{-1}\right)\end{array}$ & $k B^{-1}$,physGb & $\begin{array}{c}R_{\mathrm{a}, \text { empGb }} \\
\left(\mathrm{s} \mathrm{m}^{-1}\right)\end{array}$ & $\begin{array}{c}R_{\mathrm{a}, \text { physGb }} \\
\left(\mathrm{s} \mathrm{m}^{-1}\right)\end{array}$ \\
\hline AU-Tum & 40 & -0.20 & 0.06 & 5.95 & 7.63 & 5.02 & 1.64 & 13.70 & 11.11 \\
DK-Sor & 25 & -0.08 & 0.06 & 9.43 & 8.06 & 10.64 & 3.13 & 17.54 & 20.41 \\
FI-Hyy & 14 & -0.08 & 0.01 & 10.10 & 8.55 & 4.74 & 1.26 & 18.52 & 14.92 \\
FR-Pue & 5.5 & -0.07 & 0.03 & 10.53 & 9.17 & 5.31 & 1.34 & 20.00 & 16.13 \\
GF-Guy & 35 & -0.17 & 0.06 & 9.43 & 8.47 & 11.24 & 3.09 & 17.86 & 20.83 \\
US-Ha1 & 23 & -0.07 & 0.10 & 6.80 & 9.01 & 7.35 & 1.95 & 15.87 & 13.89 \\
\hline
\end{tabular}

Table S2: Standard error of the regression (SER) for all sites and multiple model versions.

\begin{tabular}{lcccccc}
$\boldsymbol{G}_{1}$ version $^{\text {a }}$ & AU-Tum & DK-Sor & FI-Hyy & FR-Pue & GF-Guy & US-Ha1 \\
\hline fcoupled, air, nt & 0.160 & 0.156 & 0.065 & 0.052 & 0.185 & 0.159 \\
empGb, air, nt & 0.171 & 0.228 & 0.070 & 0.046 & 0.255 & 0.166 \\
physGb, air, nt & 0.169 & 0.238 & 0.067 & 0.045 & 0.268 & 0.169 \\
empGb, surface, nt & 0.167 & 0.211 & 0.065 & 0.044 & 0.248 & 0.161 \\
physGb, surface, nt & 0.166 & 0.226 & 0.064 & 0.044 & 0.263 & 0.164 \\
empGb, surface, dt & 0.175 & 0.231 & 0.076 & 0.049 & 0.255 & 0.169 \\
physGb, surface, dt & 0.173 & 0.245 & 0.076 & 0.050 & 0.272 & 0.173 \\
\hline a denoted as: $G_{\text {a }}$ formulation, air or surface conditions, nighttime (nt) or daytime (dt) NEE-partitioning.
\end{tabular}




\section{Figures}

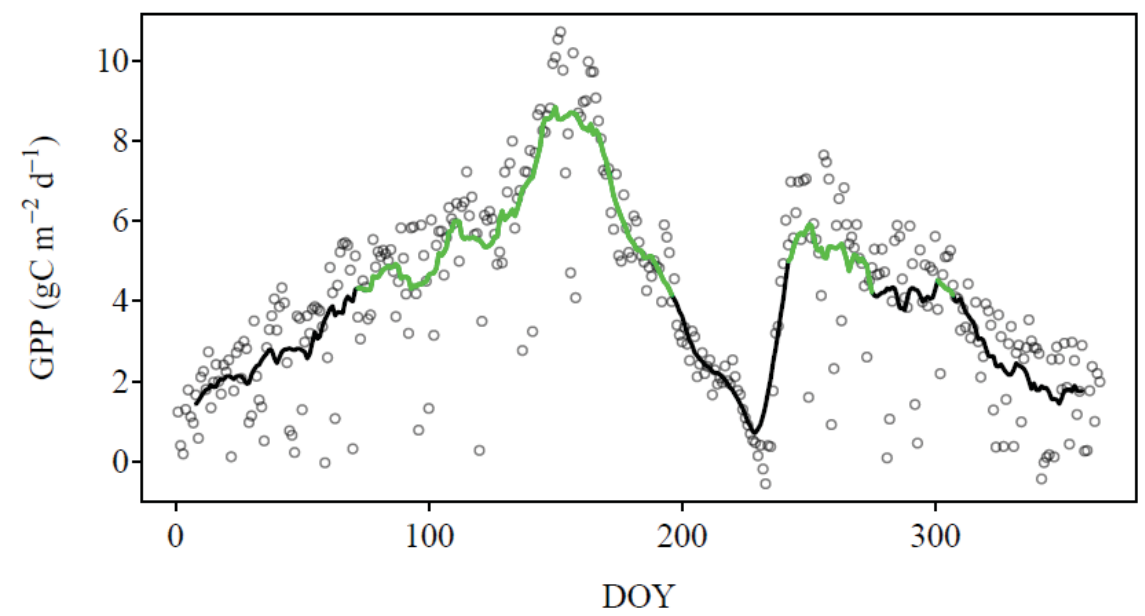

Figure S1 GPP-based growing season filter used in this study shown for the site FR-Pue for the year 2002. Grey dots are daily GPP sums, the black line is the smoothed GPP time series (window width $=15$ days), and the green line is the time period that was considered to be in the growing season.
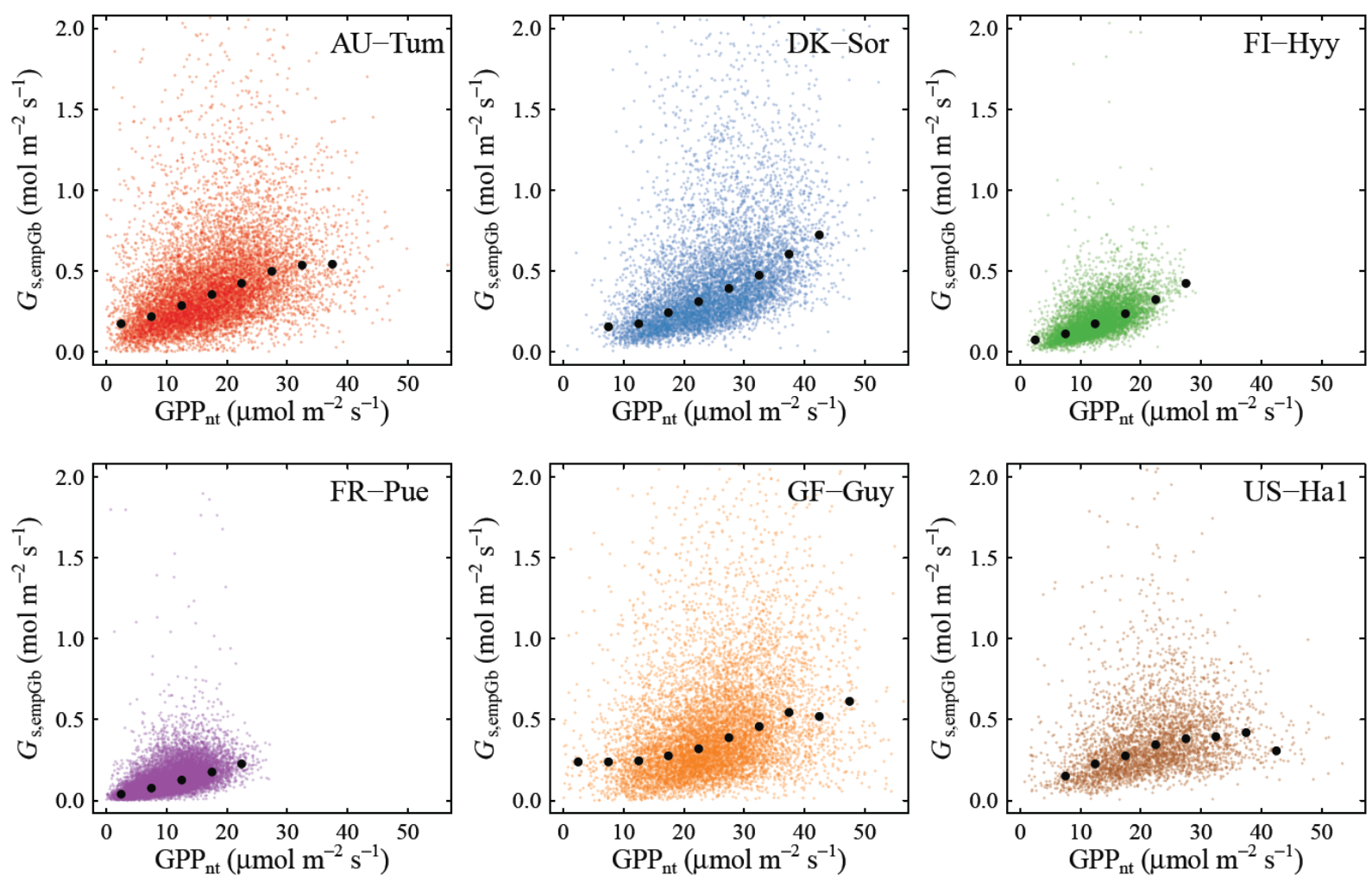

Figure S2 Surface conductance ( $G_{\mathrm{s}}$, calculated using the $G_{\mathrm{a}}$ version $G_{\mathrm{a}, \text { empGb }}$ (Eq. (5)) plotted against GPP (derived from NEE using the nighttime approach according to Reichstein et al. (2005)). Black dots indicate the median of the respective bins. 

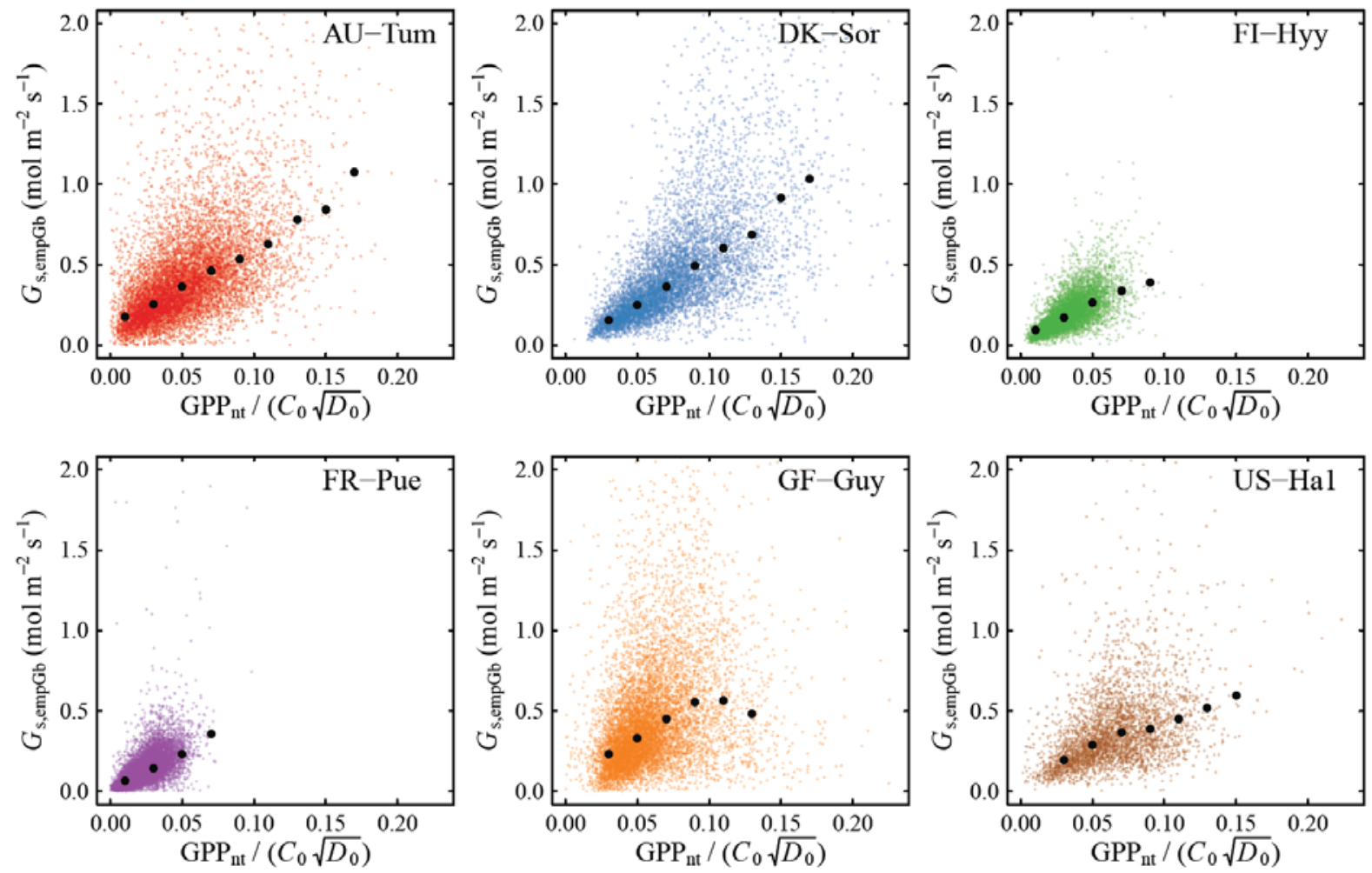

Figure S3 Surface conductance ( $G_{s}$, calculated using the $G_{\mathrm{a}}$ version $G_{\mathrm{a}, \text { empGb }}$ (Eq. (5)) plotted against GPP / $\left(C_{0} \sqrt{\boldsymbol{D}_{\mathbf{0}}}\right)$ (with GPP derived from NEE using the nighttime approach according to Reichstein et al. (2005)). Black dots indicate the median of the respective bins. 


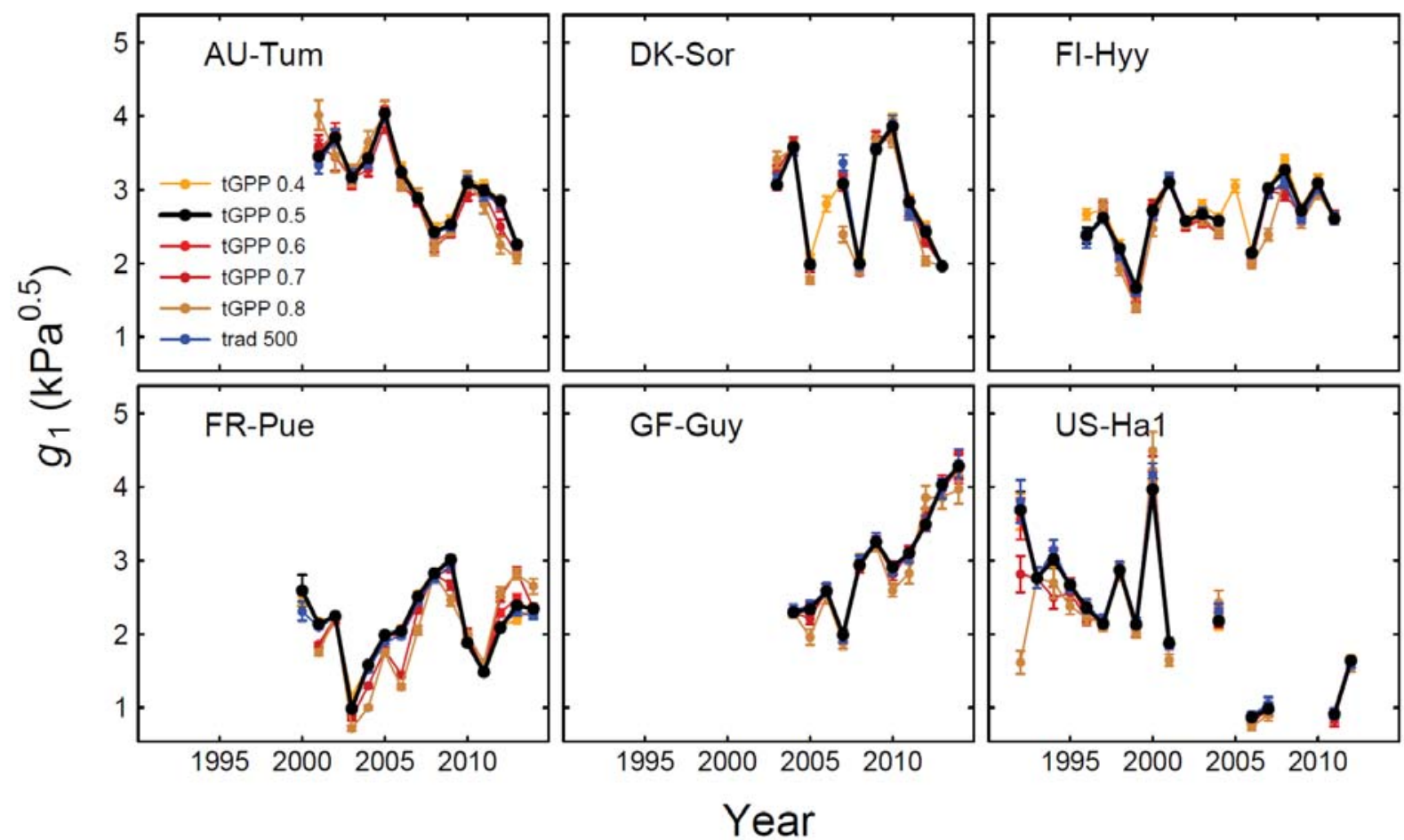

Figure S4 Sensitivity of annual $G_{1}$ estimates to alternative data filters with respect to growing season and radiation thresholds. $t G P P$ 0.4, $t G P P \quad 0.5$, tGPP 0.6, tGPP 0.7, and $t G P P 0.8$ denote GPP thresholds corresponding to $40,50,60,70$, and $80 \%$, respectively, of the $95^{\text {th }}$ percentile of smoothed daily GPP time series, above which the data were considered to be in the growing season (see Fig. S1). trad 500 denotes an increased radiation threshold of $500 \mu \mathrm{mol} \mathrm{m} \mathrm{m}^{-2}$. The thick black line denotes the filter as applied in this study (GPP threshold of $0.5(50 \%)$ and radiation threshold of $200 \mu \mathrm{mol} \mathrm{m} \mathrm{m}^{-2} \mathrm{~s}^{-1}$ ). Error bars indicate standard errors. 


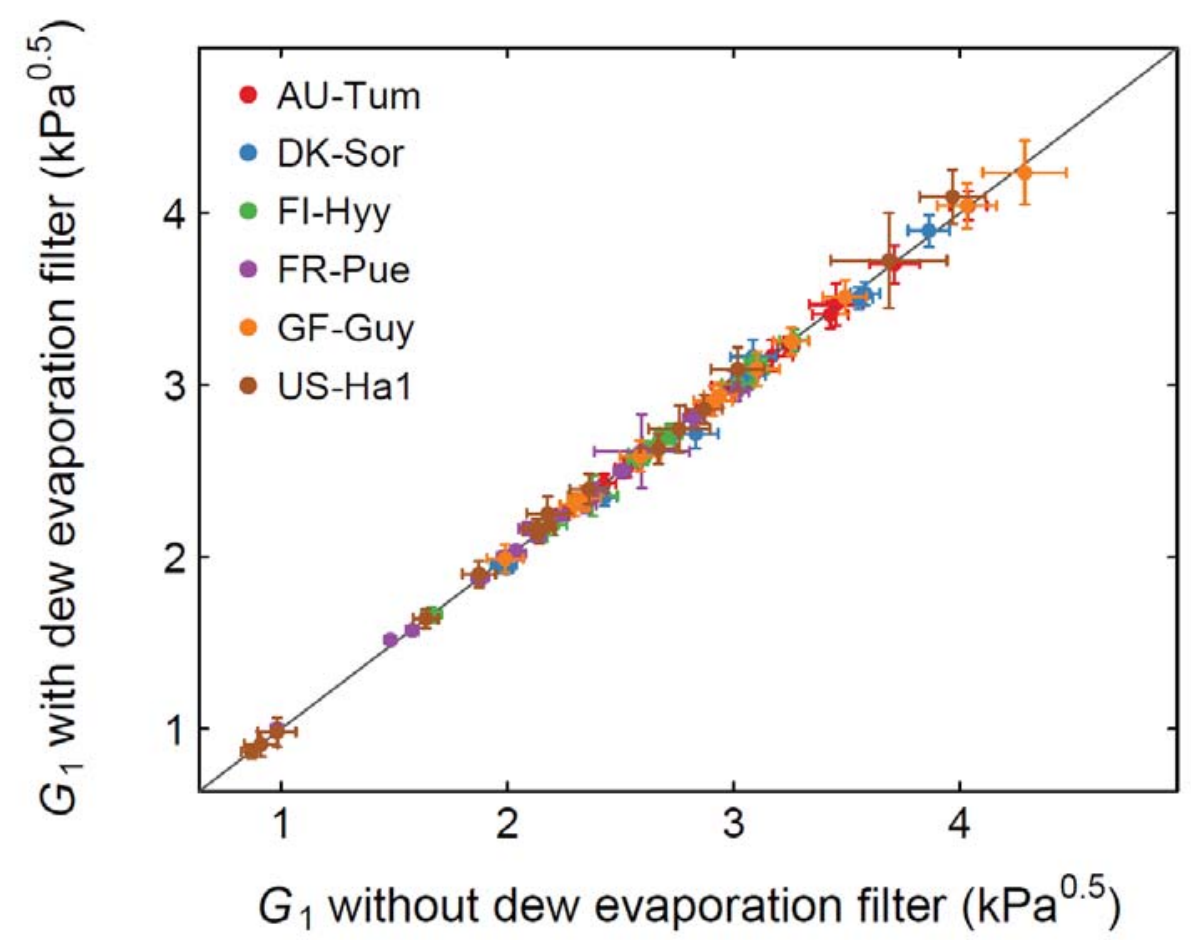

Figure S5 Effect of the implemented dew evaporation filter on the estimated $G_{1}$. The filter excludes time periods that have a high probability of being affected by dew evaporation.

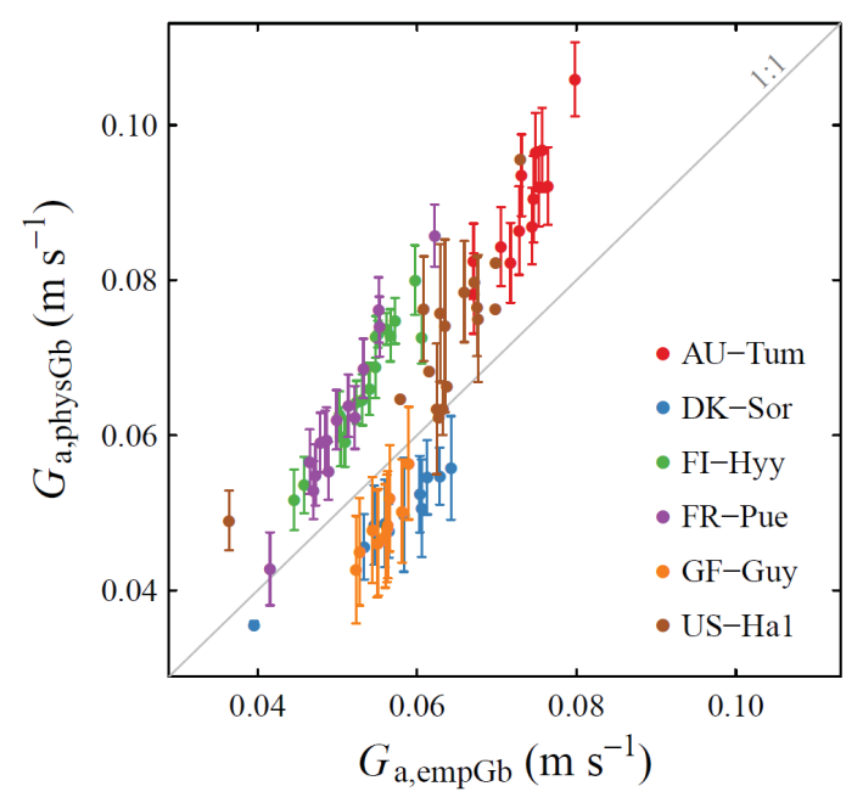

Figure $\mathbf{6} 6$ Comparison of median annual values of aerodynamic conductance $\left(G_{\mathrm{a}}\right)$ calculated from different formulations (Eqs. $(5,6))$. 

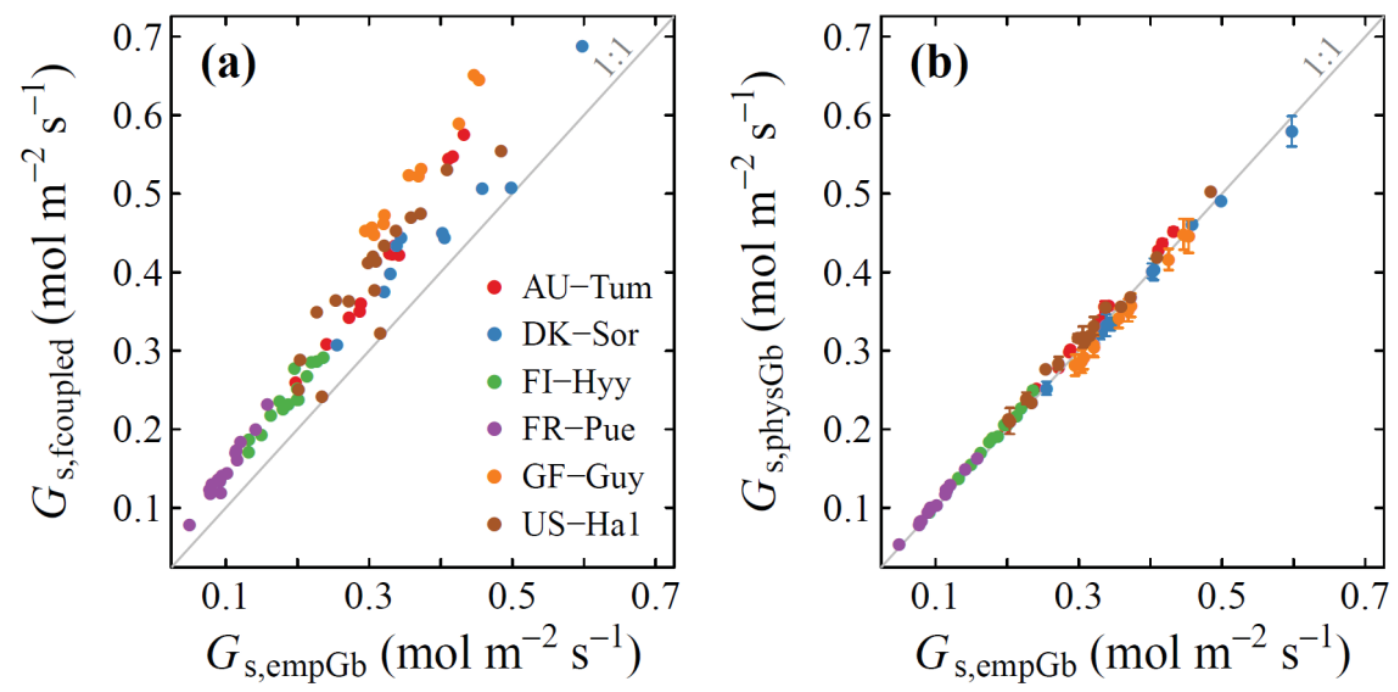

Figure S7 Same as Figure S for surface conductance $\left(G_{s}\right)$.

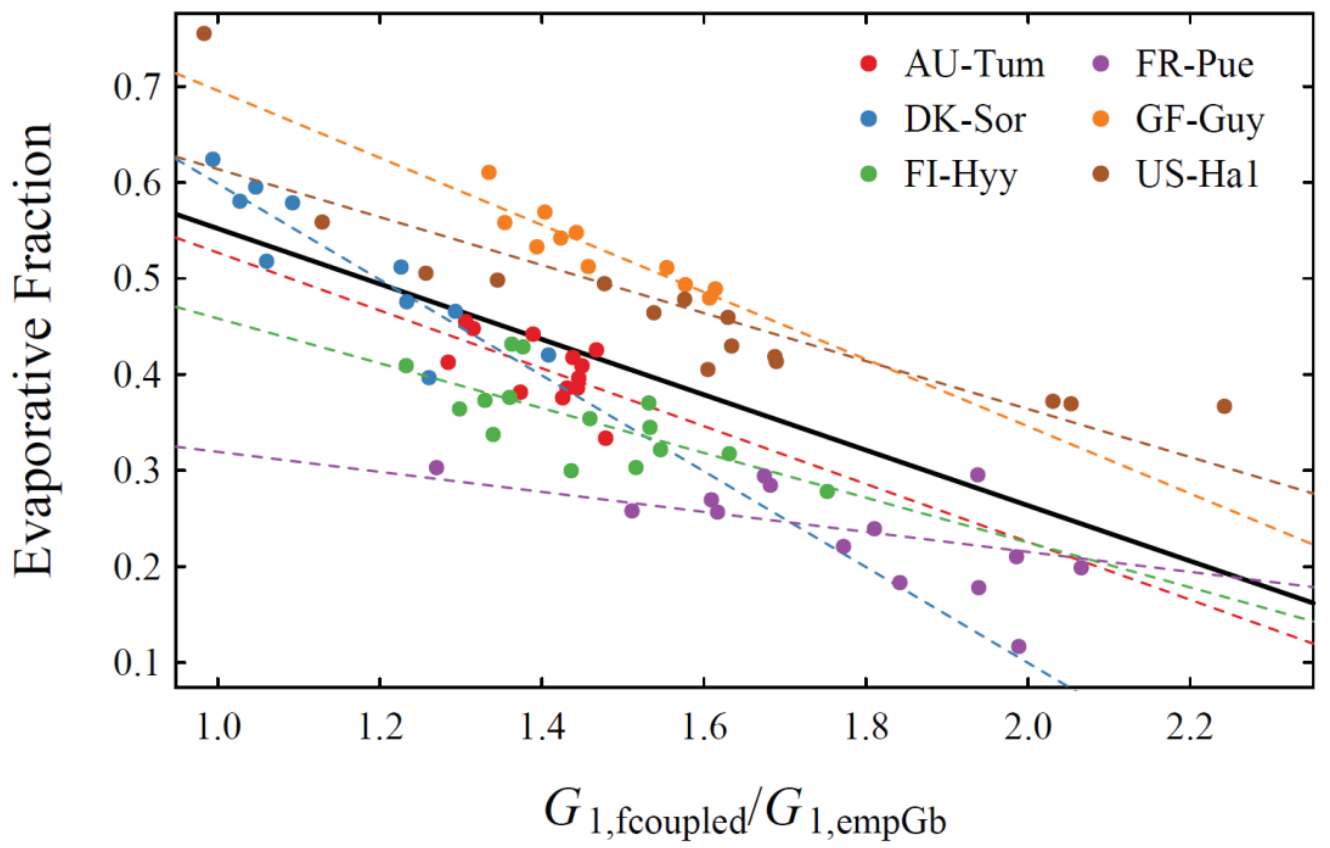

Figure $\mathbf{8 8}$ The relation between evaporative fraction $\left(\lambda E / R_{\mathrm{n}}\right)$ and the effects of $G_{\mathrm{a}}$ on the estimated $G_{1}$. Dashed colored lines and the bold black line are ordinary least squares fits for individual sites and all sites, respectively. 

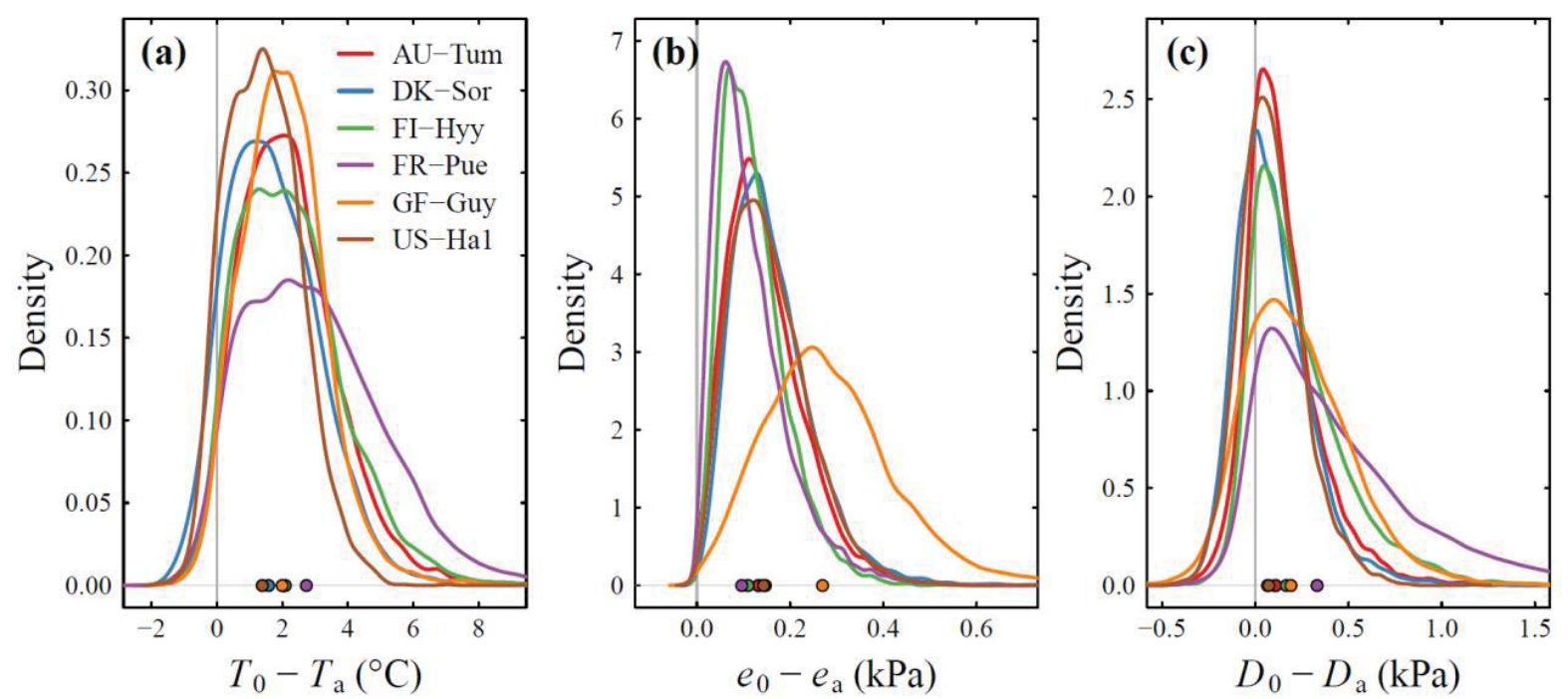

Figure S9 Deviations of (a) Canopy surface temperature, (b) vapor pressure, and (c) the resulting vapor pressure deficit (as in Fig. 4) from those measured in the air. Surface conditions are derived from inverted bulk transfer equations (Eqs. (7) - (9)) with $G_{\mathrm{a}}$ estimated from Eq. (5).

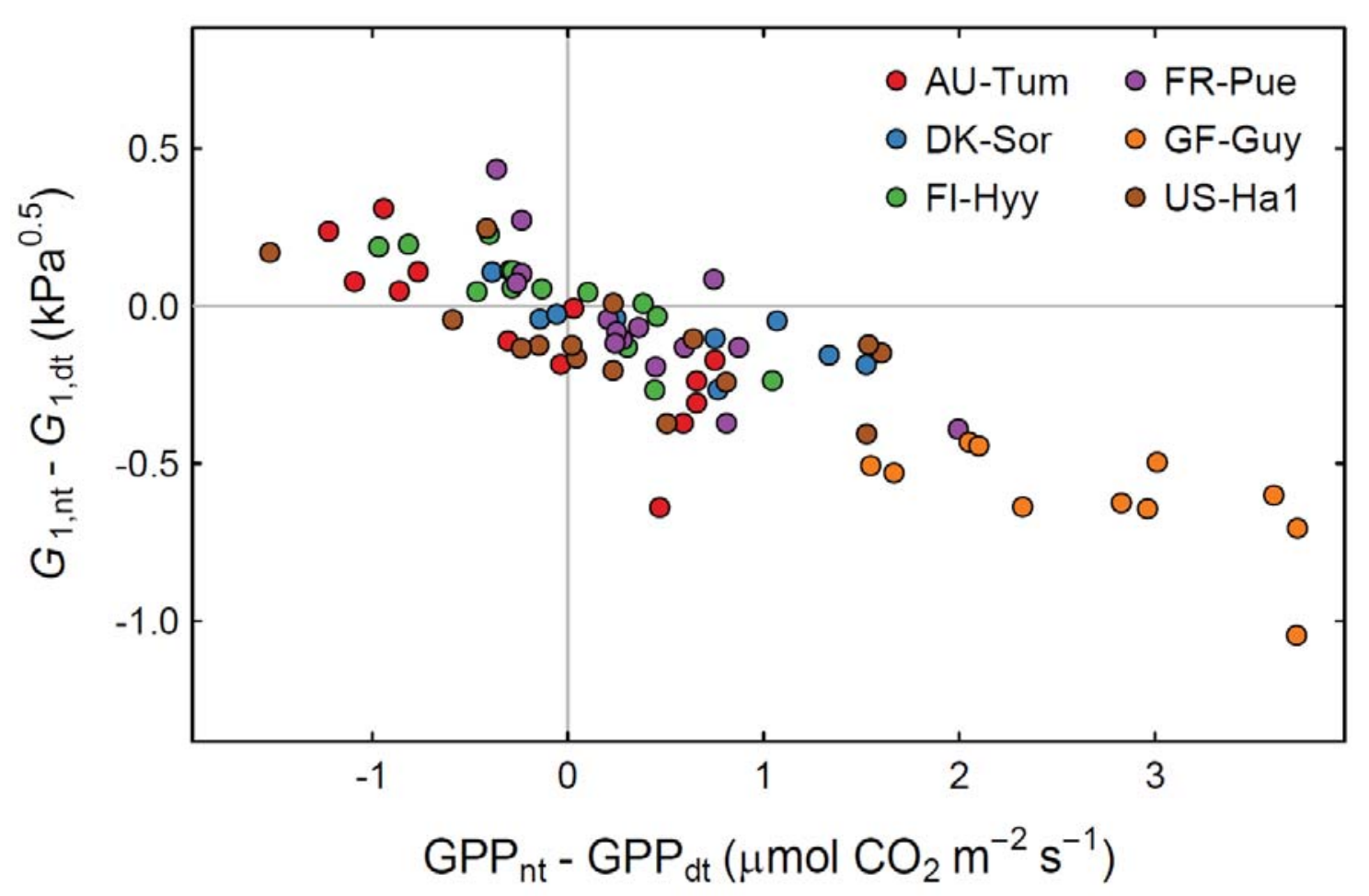

Figure S10 Differences in GPP as a result of the two different NEE partitioning algorithms (nighttime approach (Reichstein et al., 2005) and daytime approach (Lasslop et al., 2010)) and their effects on $G_{1}$. 


\section{References}

Lasslop G, Reichstein M, Papale D et al. (2010) Separation of net ecosystem exchange into assimilation and respiration using a light response curve approach: critical issues and global evaluation. Global Change Biology, 16, 187-208.

Liaw A, Wiener M (2002) Classification and Regression by randomForest. $R$ News, 2, 18-22.

Massman W (1999) A model study of $\mathrm{kB}_{\mathrm{H}}{ }^{-1}$ for vegetated surfaces using 'localized near-field' Lagrangian theory. Journal of Hydrology, 223, 27-43.

Owen P, Thomson W (1963) Heat transfer across rough surfaces. Journal of Fluid Mechanics, 15, 321-334.

Paulson CA (1970) The mathematical representation of wind speed and temperature profiles in the unstable atmospheric surface layer. Journal of Applied Meteorology, 9, 857-861.

Reichstein M, Falge E, Baldocchi D et al. (2005) On the separation of net ecosystem exchange into assimilation and ecosystem respiration: review and improved algorithm. Global Change Biology, 11, 1424-1439.

Su Z, Schmugge T, Kustas W, Massman W (2001) An evaluation of two models for estimation of the roughness height for heat transfer between the land surface and the atmosphere. Journal of Applied Meteorology, 40, 1933-1951.

Thom A (1972) Momentum, mass and heat exchange of vegetation. Quarterly Journal of the Royal Meteorological Society, 98, 124-134.

Verhoef A, De Bruin H, Van Den Hurk B (1997) Some practical notes on the parameter kB-1 for sparse vegetation. Journal of Applied Meteorology, 36, 560-572.

Verma S (1989) Aerodynamic resistances to transfers of heat, mass and momentum. In: Estimation of areal evapotranspiration. (eds Black A, Spittlehouse D, Novak M, Price D), pp 13-20, IAHS Publication No. 177. 